\title{
Review on texturization effects in thermoelectric oxides
}

\author{
Rishi Prasad ${ }^{1} \cdot$ Shekhar D. Bhame ${ }^{1}$ (]
}

Received: 19 September 2019 / Accepted: 28 December 2019 / Published online: 9 January 2020

(c) The Author(s) 2020

\begin{abstract}
Sustainable energy sources and energy-harvesting technologies have been researched for decades. Thermoelectric conversion is currently one of the primary foci in this area. Thermoelectric research has been concentrated into two parts-(i) strategies to enhance the efficiency of existing thermoelectric materials and (ii) development of new materials with promising thermoelectric parameters. Although such strategies have led to the improvement of thermoelectric non-oxide-based materials, the limitations possessed by them does not allow to be used at high temperatures. Due to the same reason, oxide-based materials have gained much attention. Here, we discuss about the oxide thermoelectric materials in detail and the effect of texturization on their morphology and transport properties. There is a lot of scope available for such class of materials for high-temperature applications.
\end{abstract}

Keywords Thermoelectric review $\cdot$ Oxide thermoelectrics $\cdot$ Effect of texturization $\cdot$ Thermoelectric figure of merit

\section{Introduction}

Renewable energy has been one of the very widely studied topics since the past few decades due to the rising problem of fulfilling the energy demands. The increasing demand for oil and electricity is a much-known fact that cannot be ignored. On a global average, more than $70 \%$ of the energy generated is wasted one way or the other. TE energy harvesting is promising in providing opportunities to harvest the waste heat that is rejected out of the automobile exhausts, chimneys of factories, etc. In this review, we will concentrate only on thermal energy harvesting. Thermoelectric materials can be used as a source for both power generation and cooling devices [1]. Metal-based thermoelectric conversion materials were studied earlier followed by semiconducting materials. Since metallic TE materials are not ideal for hightemperature applications as they are prone to corrosion and hamper the conductivity, oxide-based thermoelectric materials have gained much attention. The world market of thermoelectric generators is $25-50$ million\$ per year and that for

Shekhar D. Bhame

Shekhar.bhame@sitpune.edu.in

1 Symbiosis International (Deemed University), Symbiosis Institute of Technology, Lavale, Pune, Maharashtra 412115, India cooling devices is $200-250$ million\$ per year that attracts a lot of research in this area [2].

Ioffe in the 1930s proposed the idea that semiconductors act as better thermoelectric materials than metals that were previously used [3]. Though Altenkirch (in 1909) was the first to establish a mathematical expression which relates physical properties of thermoelectric materials and the efficiency of simplified thermopile or thermoelectric generators, his equation contained various parameters like electromotive force, thermal, and electrical resistances etc., Ioffe was the first to quantify $Z$ (Thermoelectric figure of merit) by integrating all the variables introduced by Altenkirch into one term as $Z[4,5]$.

The maximum energy conversion efficiency is given by $\eta_{\max }$ and is defined as:

$\eta_{\text {max }}=\frac{T_{\text {hot }}-T_{\text {cold }}}{T_{\text {hot }}} \frac{M-1}{M+\frac{T_{\text {cold }}}{T_{\text {hot }}}}$,

where $M=\left(1+Z T_{\text {avg }}\right)^{1 / 2}, T_{\text {avg }}$ being the average temperature, $Z$ is the thermoelectric figure of merit, and $T_{\text {hot }}$ and $T_{\text {cold }}$ are temperatures of the hot and cold end of the module, respectively $[6,7]$. The potential of a thermoelectric material for the application is measured with the help of a term called as the dimensionless thermoelectric figure of merit $(Z T)$ which measures the maximum heat conversion into electricity. $Z T$ is given by: 
$Z T=\frac{S^{2} \sigma}{\kappa_{\mathrm{e}}+\kappa_{1}+\kappa_{\text {bip }}} T$,

where $S(\mathrm{~V} / \mathrm{K})$ is the Seebeck coefficient, $\sigma(\mathrm{S} / \mathrm{m})$ is electrical conductivity, and $\kappa_{\mathrm{e}}, \kappa_{\mathrm{l}}$, and $\kappa_{\text {bip }}(\mathrm{W} / \mathrm{m} \mathrm{K})$ are the electronic, lattice, and bipolar contribution to thermal conductivity due to bipolar effects $[8,9]$. The power factor $S^{2} \sigma$ is optimized in narrow gap semiconductors as a function of carrier concentration (typically $\sim 10^{19}-10^{20}$ carriers $/ \mathrm{cm}^{3}$ ).

Figure 1 shows the optimization of $Z T$ by tuning the carrier concentration for $\mathrm{Bi}_{2} \mathrm{Te}_{3}[10]$. It was observed that maximum $Z T$ could be obtained on tuning the carrier concentration to be between $\sim 10^{19}$ to $\sim 10^{20}$ carriers $/ \mathrm{cm}^{3}$.

Since Wiedemann-Franz law relates electrical and thermal conductivities as directly proportional quantities $\left(\kappa_{\mathrm{e}}=L T \sigma\right)$, the quantities $S, \sigma$, and $\kappa$ for a conventional 3D crystalline system cannot be varied independently to give a high $Z T$ value. Because what is desired is a high Seebeck coefficient, high electrical conductivity, and low thermal conductivity. If electrical conductivity is low for a material, carrier concentration has to be increased. As we increase the carrier concentration, electrical conductivity would increase. This, in turn, would reduce the Seebeck coefficient and increase the electrical contribution to thermal conductivity. The complex relationships of these parameters can be summarized in the Fig. 3 and also in the form of the equation as:

$S=\frac{8 \pi K_{\mathrm{B}}^{2}}{3 e h^{2}} m^{*} T\left(\frac{\pi}{3 n}\right)^{2 / 3}$,

$\sigma=n e \mu=\frac{n e^{2} \tau}{m^{*}}$

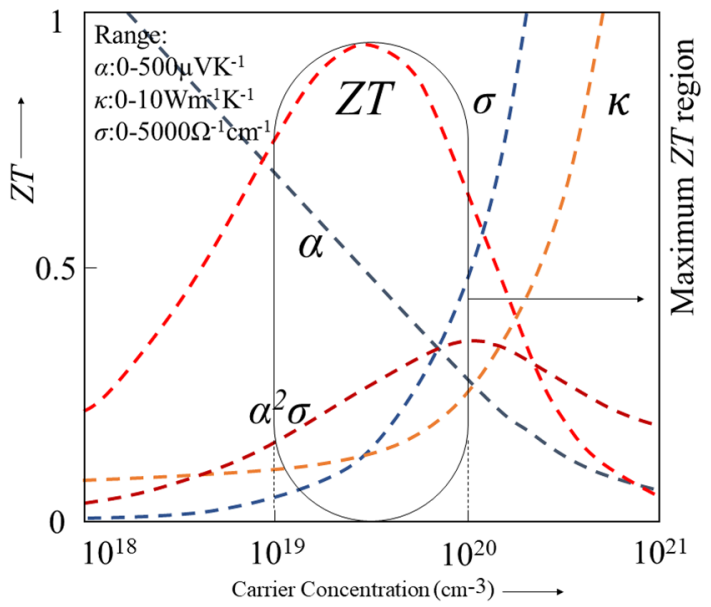

Fig. 1 Optimization of $Z T$ by tuning the carrier concentration for $\mathrm{Bi}_{2} \mathrm{Te}_{3}$. Image adapted with permission from Snyder et al. [10], Springer Nature
$\mathrm{K}_{\text {tot }}=\kappa_{\text {lat }}+\kappa_{\text {ele }}+\kappa_{\text {bip }}=\kappa_{\text {lat }}+L \sigma T+\kappa_{\text {bip }}$,

where $K_{\mathrm{B}}$ is a Boltzmann constant, $m^{*}$ is density of states effective mass, $h$ is the Planks constant $\left(6.6260 \times 10^{-34} \mathrm{~m}^{2} \mathrm{~kg} / \mathrm{s}\right), n$ being carrier concentration, $e$ is charge of an electron $\left(1.6021 \times 10^{-19}\right.$ coulombs $), \mu$ is carrier mobility, $\tau$ is relaxation time, $\mathrm{K}_{\text {tot }}, \kappa_{\text {lat }}, \kappa_{\text {ele }}, \kappa_{\text {bip }}$ being total, lattice, electronic and bipolar contribution to thermal conductivity, and $L$ is Lorentz number $\left(2.44 \times 10^{-8} \mathrm{~W} \Omega / \mathrm{K}^{2}\right)[11$, 12]. $\kappa_{\text {bip }}$ is usually observed for relatively narrow band-gap materials, which leads to the decrease of TE efficiency. This effect is the consequence of the diffusion of both electrons and holes in the same direction. The minority conductors get thermally exited through the bandgap leading to the cancellation of net charge in the conduction band. They reduce the Seebeck coefficient as the minority charge carriers contribute significantly. This is generally observed for very narrow bandgap semiconductors $\left(E_{\mathrm{g}}<0.5 \mathrm{eV}\right)[13,14]$. What is commonly observed is for an ideal metal, they possess high electrical conductivity and low thermal conductivity. Glasses exhibit high thermal conductivity and low electrical conductivity. Since a mixture of these two properties would be optimum for a thermoelectric material, such materials are termed as "phonon glass electron crystal" since it would possess high thermal conductivity like glass and still possess high electrical conductivity like an ordered crystal. It has been reported by Dresselhaus that as the dimension of material decreases and approaches a nanometer scale, it possibly causes differences in the density of states and gives rise to quantum confinement effects allowing new methods to tailor $S, \sigma$, and $\mathrm{K}$ values independently to achieve high $Z T$ [15].

Although there are significant reports of various class of thermoelectric materials exhibiting low thermal conductivity and high electronic conductivity leading to high power factor and $Z T$, as shown in Fig. 2. Operating them at a high temperature for waste heat conversion is still a concern. A number of concerns such as toxicity, low melting point, high oxidation tendency, and stability at high temperature are yet to be addressed in detail.

Figure 2 shows the development of high $Z T$ materials over the year for non-oxide-based systems adapted from Zhang et al. [11]. The extreme left indicates the state-of-the-art materials, mid-portion indicates the improvement till close to 2010 , and the last part shows very high $Z T$ obtained in the recent decade. Few of the newly included materials other than the reference quoted above are $\mathrm{PbTe}-\mathrm{SrTe}, \mathrm{Cu}_{2} \mathrm{Se} / \mathrm{CNT}$, $\mathrm{PbSe}+2 \% \mathrm{HgSe}$, and Na-doped $\mathrm{SnS}$.

Oxides are considered to be more stable with a high melting point, relatively less toxicity, and cheap. During the initial days of development, thermoelectric community had ignored this class of materials due to the low conductivity of carriers and ionic nature. However, due to the features that possess, they have been investigated since past 2 decades. 
Fig. 2 The development of high $Z T$ materials over the year for non-oxide-based systems [adapted with permission from Zhang et al. [11], Elsevier]

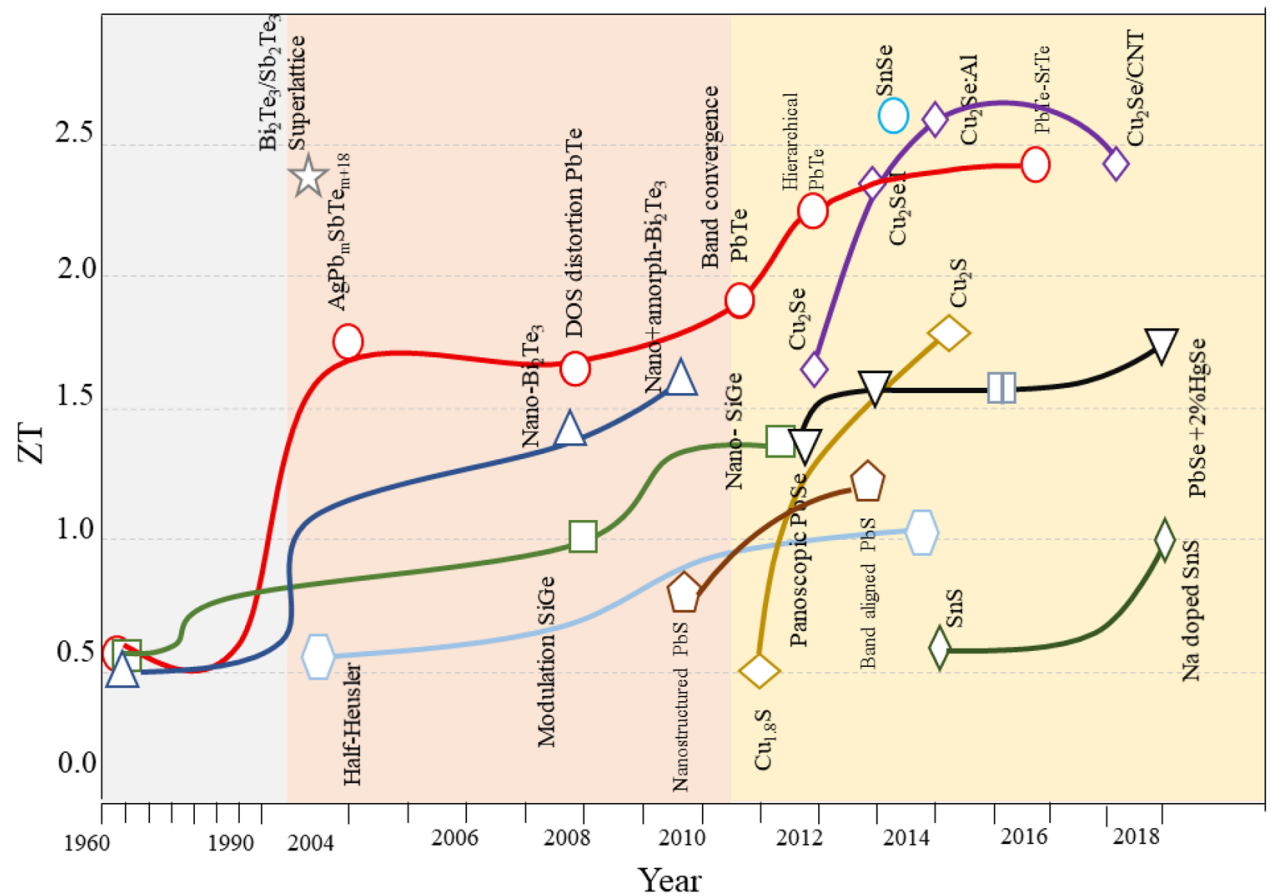

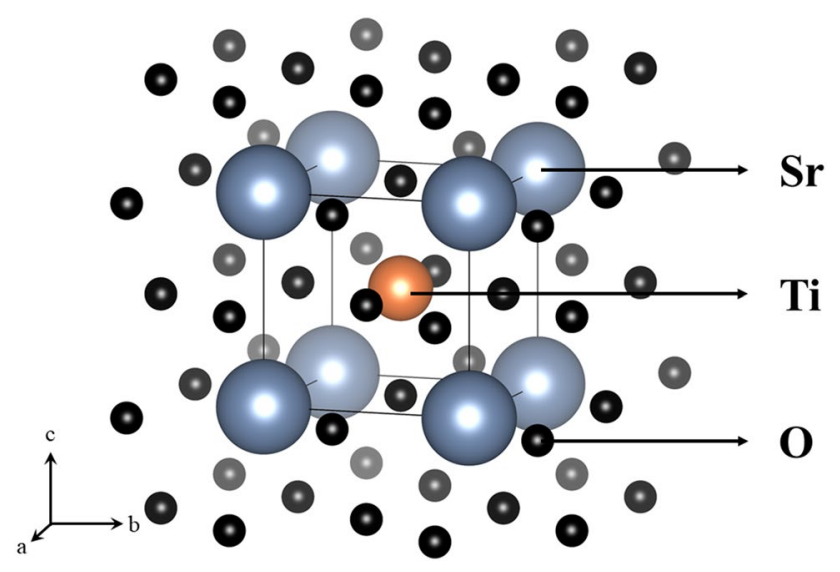

Fig. 3 Crystal structure of STO simulated using VESTA

Their electronic properties can be tuned by manipulating their crystal structures, chemical compositions, and doping concentrations. As thermoelectric oxides exhibit high covalent and ionic character, they tend to show high thermal conductivity. Hence, doping them with suitable elements is necessary. It has been seen that, in solids that show poor thermal conductivity, the phonon mean free path is in the range of interatomic distance. Hence, doping the right element not only alters electronic properties but also alters the thermal properties [16]. A number of oxide-based thermoelectric materials have been reported. A few promising ones to mention are $\mathrm{SrTiO}_{3}, \mathrm{Ca}_{3} \mathrm{Co}_{4} \mathrm{O}_{9}, \mathrm{Na}_{x} \mathrm{CoO}_{2}, \mathrm{ZnO}, \mathrm{In}_{2} \mathrm{O}_{3}$, and $\mathrm{BiCuSeO}$.

\section{$\mathrm{SrTiO}_{3}$}

Strontium titanium oxide (STO) is an $n$-type perovskite oxide. They have a cubical crystal structure and belong to the space group of $\mathrm{pm} \overline{3} \mathrm{~m}$ [17] with a very high melting point of $2353 \mathrm{~K}$. Since they have a very high melting point, it is a potential high-temperature thermoelectric candidate [18].

In Fig. 3, the periwinkle blue sphere indicates $\mathrm{Sr}$ atoms, brown indicates Ti atoms, and black sphere indicates oxygen atoms. STO has a wide bandgap of $3.2 \mathrm{eV}$. STO shows promising Seebeck coefficient, electrical conductivity, carrier mobility, and large effective mass $\left(m^{*} \sim 10 m_{\mathrm{o}}\right)$. The high Seebeck coefficient is attributed to the sixfold degeneracy of $3 \mathrm{~d}-\mathrm{t} 2 \mathrm{~g}$ conduction band of Ti [19]. The carrier concentration of STO can be controlled by adequate doping of elements to transform it from insulating to semiconducting with a concentration of $\sim 10^{21} \mathrm{~cm}^{-3}$ [20]. It has been seen that $\mathrm{Nb}$ and La doping makes way for STO single crystals as an effective thermoelectric material. Okuda et al. reported very high Seebeck coefficient $\left(2800-3600 \mu \mathrm{W} / \mathrm{K}^{2} \mathrm{~m}\right)$ and power factor (28-36 $\mu \mathrm{V} /\left(\mathrm{K}^{2} \mathrm{~cm}\right)$ for La-substituted STO $\left(\mathrm{Sr}_{1-x} \mathrm{La}_{x} \mathrm{TiO}_{3}\right)$ which was comparable to $\mathrm{Bi}_{2} \mathrm{Te}_{3}$ [21]. However, since they show high thermal conductivity $(6-12 \mathrm{~W} / \mathrm{m} / \mathrm{K}$ for singlecrystalline STO) obtaining a high $Z T$ was limited [22], since then, a lot of studies has been done on reducing the thermal conductivity to enhance ZT. In 2003, Muta et al. tried to understand the effect of rare-earth element doping in the STO crystal. Not much difference in electrical conductivity was seen on varying the substituent rare-earth element. 
However, in the case of thermal conductivity, the dopant had a strong influence. La and Sm showed a decrease in thermal conductivity as temperature increased. Gd, Dy, and Y doping led to the least thermal conductivity without much dependence on the temperature. This trend was attributed to temperature-independent phonon impurity scattering. The order of thermal conductivity on doping is $\mathrm{La}>\mathrm{Sm}>\mathrm{Gd}>\mathrm{Y}>\mathrm{Dy}$ with Dy being the element of substitution with least thermal conductivity $(\sim 2.2 \mathrm{~W} / \mathrm{m} / \mathrm{K})$ which naturally led to better $Z T$ than the rest as Seebeck coefficient and electrical conductivity was almost the same [23]. Since $\mathrm{Nb}$ and La have one of the most structural tolerance for doping in STO and since it possesses highest electrical conductivity, B site substitution with $\mathrm{Nb}$ gained much attention [20]. Few other rare-earth substitutions in the STO matrix along with reduced sintering time were reported by Kovalivisky et al. $\mathrm{Pr}, \mathrm{Nd}$, and Sm incorporation showed promising electronic conductivity as compared to $\mathrm{La}, \mathrm{Ce}, \mathrm{Gd}$, Dy, and Y doping. However, small cation elements like Dy and Y gave rise to better Seebeck coefficient. Oxygen-deficient perovskite layers present in Nd-, Sm-, and Dy-doped STO led to phonon scattering leading to $Z T$ as high as 0.42 at $1190-1225 \mathrm{~K}$ [24]. Tungsten substitution in the STO was performed by Kovalivisky et al. Tungsten substitution at the B site greatly increased the electrical conductivity without affecting the Seebeck coefficient to a great extent. Tungsten is interesting as it can donate two electrons per $\mathrm{W}$ cation and also scatters the phonons due to mass fluctuation in STO. While a $Z T$ of 0.24 was reached at $1300 \mathrm{~K}$ by substituting 0.06 portion of $\mathrm{W}$, on codoping $\mathrm{W}$ and $\mathrm{Nb}$ in $\mathrm{STO}\left(\mathrm{Sr}_{0.97} \mathrm{Ti}_{0.8} \mathrm{Nb}_{0.17} \mathrm{~W}_{0.03} \mathrm{O}_{3 \pm \delta}\right)$ resulted in a $Z T$ of 0.28 at $1270 \mathrm{~K}$. Better performance due to $\mathrm{Nb}$ codoping was assigned to the phase separation and phonon scattering [25]. Kovalivisky et al. reported the effect of Pr substitution. Results show that Pr leads to an increase in electrical conductivity reducing the Seebeck coefficient. At the same time, thermal conductivity reduction was also observed and maximum reduction in thermal conductivity was found for $x=0.30$ in $\mathrm{Sr}_{1-x} \mathrm{Pr}_{x} \mathrm{TiO}_{3}$. However, a $Z T$ of $\sim 0.34$ at $1173 \mathrm{~K}$ was obtained for $x=0.10$ [26]. Improvising the electrical conductivity in oxide-based system is crucial and this was addressed by Akin et al. by creating the oxygen vacancies. They could successfully improvise the electrical conductivity by creating A site vacancies in La-doped STO leading to oxygen loss that leads to improvement in electrical conductivity [27]. However, clarity on the influence of such vacancies on thermoelectric properties was further established by Lu et al. They obtained a ZT of 0.4 at $973 \mathrm{~K}$ (for $x=0.15$ in $\mathrm{Sr}_{1-3 x / 2} \mathrm{La}_{x} \mathrm{TiO}_{3-\delta}$ ) by tuning the A site and oxygen vacancies along with mixed valent $\mathrm{Ti}^{3+}$ and $\mathrm{Ti}^{4+}$ that held responsible for the improvement [28]. Most recently in 2018, Srivastava et al. reported promising $Z T$ of 0.36 $(900 \mathrm{~K})$ and $0.38(1000 \mathrm{~K})$ for $\mathrm{Cu}$ and $\mathrm{Fe}$ inclusion, respectively, in $\mathrm{Sr}_{0.8} \mathrm{La}_{0.067} \mathrm{Ti}_{0.8} \mathrm{Nb}_{0.2} \mathrm{O}_{3-\delta}$ system. As the resistivity was decreased, an increase in power factor up to $75 \%$ was reported. It has to be noted that the reduction of thermal conductivity was most effective in the case of Fe inclusion than the $\mathrm{Cu}$ inclusion as $\mathrm{Fe}$ acted as a better phonon scattering centre [22]. Electrons confined in quantum wells with dimensionality narrower than de-Broglie wavelength results in 2D electron gas that exhibit exotic electronic properties. 2D electron well enhances Seebeck coefficient for STO as carrier electrons are more localized in STO than in heavy metals as it is an insulator [18]_ENREF_93_ENREF_93. High Seebeck coefficient has been seen for one atom thick STO layers containing 2D electron gas (2DEG). Seebeck coefficient of up to $850 \mu \mathrm{V} / \mathrm{K}$ leading to a $Z T_{2 \mathrm{DEG}}$ of 2.4 and $Z T_{\text {eff }}$ of $\sim 0.24$ (including the barrier layer) was reported by Ohta et al. [29]. Very recently, $\mathrm{Nb}$-doped $\mathrm{SrTiO}_{3} / \mathrm{rGO}$ composite was explored. The cationic vacancies, oxygen vacancies due to rGO, and heterointerfaces lead to increased phonon scattering. Mobility of charge carriers dramatically increased due to the cationic vacancies and heterointerfaces. These features lead to a high power factor of $\sim 1.98 \mathrm{~mW} /$ $\mathrm{K}^{2} \mathrm{~m}$ promising $Z T$ of 0.29 at $1180 \mathrm{~K}$ [30]. Tkach et al. in 2018 made use of a unique two-step firing process to obtain bimodal distribution of $20 \% \mathrm{Nb}$-doped STO fine particles (particles smaller size $\sim 270 \mathrm{~nm}$ ) with a grain size of $\sim 2.3 \mu \mathrm{m}$ and $59 \mu \mathrm{m}$ while for the coarse particles (particles with larger size $\sim 800 \mathrm{~nm}$ ) exhibited an average grain size of $\sim 8 \mu \mathrm{m}$. The lower number of grain boundaries within the large connected grains in fine size STN20 leads to better electrical conductivity ( $328 \mathrm{~S} / \mathrm{cm}$ at $970 \mathrm{~K}$ ). Energy filtering effects in the fine size STN20 further reportedly lead to an increase in Seebeck coefficient with temperature. The power factor of this material obtained was $13.4 \mu \mathrm{W} / \mathrm{K}^{2} \mathrm{~cm}$ which is comparable with that of state-of-the-art thermoelectric material $\mathrm{Bi}_{2} \mathrm{Te}_{3}$ and finally leading to a $Z T$ of 0.36 at $970 \mathrm{~K}$ [31]. Meanwhile, a much simpler approach was followed by Ekren et al. where a fixed amount $(0.5 \mathrm{wt} \%)$ of $\mathrm{B}_{2} \mathrm{O}_{3}$ and $0.3 \mathrm{wt} \% \mathrm{ZrO}_{2}$ were composited with $\mathrm{Sr}_{0.9} \mathrm{Nb}_{0.1} \mathrm{TiO}_{3}$ to obtain $1400 \mathrm{~S} / \mathrm{cm}$ at room temperature and $200 \mathrm{~S} / \mathrm{cm}$ at $1273 \mathrm{~K}$. A drastic improvement in electrical conductivity was seen on just $0.3 \mathrm{wt} \%$ addition of $\mathrm{ZrO}_{2}$. The dislocation density enhancement on addition of $\mathrm{ZrO}_{2}$ that leads to increased oxygen vacancies thereby increasing the carrier concentration (also helps in reduction in thermal conductivity) hold responsible for this improvement. The addition of $\mathrm{ZrO}_{2}$ also lead to the formation of uniform-sized smaller grains leading to barely irregular grain boundaries that lead to carrier mobility improvement. Lowest Seebeck coefficient and highest power factor( $\left.\sim 1000 \mu \mathrm{V} / \mathrm{m} . \mathrm{K}^{2}\right)$ were obtained for the same composition leading to a $Z T$ of 0.37 at $1015 \mathrm{~K}$ [32]. To tune the thermal conductivity, substituting $\mathrm{Ca}$ and $\mathrm{Ba}$ at the A site has resulted in lowering the same [33, 34]. However, it was reported that these dopants also supresses the power factor, thereby hampering the thermoelectric performance [35]. 
Though there were other reports of doping STO, addition of secondary phases, and tuning the $A$ and $B$ site vacancies, no further improvement in $Z T$ as reported by Kovalivisky et al. [24] has been seen till date.

\section{Effect of texturization}

Quin et al. followed a Reactive Template Grain Growth Method (RTGG) assisted tape casting method whereby a Ruddlesden-Popper-type phase $\mathrm{SrO}\left(\mathrm{SrTiO}_{3}\right)_{n}$ material was synthesised that has a multi-layered structure. They consist of alternating layer of perovskite STO and superlattice layer of SrO stalked along the $c$-axis. Where they could achieve a Seebeck Coefficient of $-399 \mu \mathrm{V} / \mathrm{k}$ at $1073 \mathrm{~K}$ without any dopant as compared to the highest Seebeck coefficient reported by $\mathrm{Gd} / \mathrm{Sm}$ doped $\mathrm{SrO}\left(\mathrm{SrTiO}_{3}\right)_{n}$ synthesised by conventional solid-state-assisted hot-pressing method $(-350 \mu \mathrm{V} / \mathrm{k}$ at $1073 \mathrm{~K})$ [36]. Such an improvement was achieved by controlling the microstructure and annealing temperature. Promising Seebeck coefficient has been reported for $\mathrm{SrTiO}_{3}$ textured using the RTGG technique by Gao et al. where the texturization induced a low thermal conductivity of $2.1 / \mathrm{Wm} / \mathrm{K}$ at $1027 \mathrm{~K}$ and Seebeck coefficient of $\sim 313$ to $\sim 328 \mu \mathrm{V} / \mathrm{K}$ within the temperature range of $230 \mathrm{~K}$ to $1027 \mathrm{~K}$ [37]. The reported thermoelectric parameters in all the cases were found to be higher for the textured samples.

\section{$\mathrm{Ca}_{3} \mathrm{CO}_{4} \mathrm{O}_{9}(\mathrm{CCO}-349)$}

The challenges of creating novel TE oxides have led to investigating a lot of materials. Layered cobaltates such as $\mathrm{Ca}_{3} \mathrm{Co}_{4} \mathrm{O}_{9}(\mathrm{CCO}-349)$ and $\mathrm{Na}_{x} \mathrm{CoO}_{2}(\mathrm{NCO}-\times 12)$ have been found to be promising candidates for thermoelectricity. One of the major steps in thermoelectric oxide materials was the discovery of $\mathrm{Na}_{x} \mathrm{CoO}_{2}$ by Terasaki et al. in 1997. This material possesses a unique conduction mechanism. The charge carriers are transported via the $\mathrm{CoO}_{2}$ layer for $p$-type conduction and phonon path is mediated through the $\mathrm{Na}^{+}$layer. They possess a highly anisotropic structure with a Seebeck coefficient of $200 \mu \Omega \mathrm{cm}$ in the plane and $100 \mu \mathrm{V} / \mathrm{K}$ resistivity giving rise to a power factor of $50 \mu \mathrm{W} /\left(\mathrm{K}^{2} \mathrm{~cm}\right)$ which was comparable to that of the traditional material $\mathrm{Bi}_{2} \mathrm{Te}_{3}$ with $40 \mu \mathrm{W} /\left(\mathrm{K}^{2} \mathrm{~cm}\right)$ [38]. This anisotropy refers to the in-plane anisotropy caused because of hexagonal lattice distortion by the square RS-type layer, CCO-349 exhibits a larger thermopower meanwhile shows very less resistivity. They have thermal stability to up to $973 \mathrm{~K}$. High carrier concentration and low thermal conductivity make it a good example of electron crystal phonon glass-type material [39]. In the layered cobaltate system, only calcium cobaltate has one cation with different oxidation state. A general representation of this system is $[\mathrm{CaCoO}]_{\mathrm{RS}}\left[\mathrm{CoO}_{2}\right]$. Where $\mathrm{RS}$ represents rock salt structure. This represents a misfit structure with a rock salt disordered layer of $\mathrm{Ca}_{2} \mathrm{CoO}_{3}$ sandwiched between $\mathrm{CdI}_{2}$ type $\mathrm{CoO}_{2}$ layers stalked along $c$-axis with $[40,41]$. These two layers share the same lattice parameters. $a=4.8270(5) \AA$, $c=10.8300(2) \AA$, and $\beta=98.136(1) \AA$. Misfit of unit cell along the $b$-axis changes the lattice parameter $b$ values as $b_{1}=4.5615(2) \AA, b_{2}=2.8173(1) \AA$ for $\mathrm{Ca}_{2} \mathrm{CoO}_{3}$ and $\mathrm{CoO}_{2}$ layer, respectively [42]. The cobaltates are said to reduce thermal conductivity due to phonon scattering from incoherent boundaries. Thermoelectric properties of CCO-349 (whisker-based single crystals) showed a high ZT of 1.2-2.7 for at $873 \mathrm{~K}$. These results show that there is a lot of potential for such materials in thermoelectric applications [43]. $Z T$ of 0.87 at $973 \mathrm{~K}$ was reported by Shikano and Funahashi for single-crystalline $\left(\mathrm{Ca}_{2} \mathrm{CoO}_{3}\right)_{0.7} \mathrm{CoO}_{2}$ misfit oxide [44]. Due to the complexity of the production of single crystals, development of polycrystalline materials is of importance. Polycrystalline material synthesis has also been reported for these materials with various substitutions like Eu [45], $\mathrm{Lu}$ [46], Ho, and Ga [47] to give promising $Z T$ values. Bismuth has been considered as one among the most promising dopant. It has shown to increase electrical conductivity and Seebeck coefficient. Bismuth also leads to a reduced thermal conductivity due to the larger size of $\mathrm{Bi}$ atoms and also their corresponding mass [48]. Silver is another promising dopant that leads to an increase in electrical conductivity and reduction in thermal conductivity because of the heavy ion. Whereas for Ag that is added as a composite mixture with CCO-349, Ag acts as a connector between the cobaltate grains leading to a decrease in the scattering of charge carriers leading to increasing conductivity at grain boundaries. While doping of $\mathrm{Ag}^{+}$ions increases the thermopower and charge mobility along with charge concentration, composite decreases thermopower due to metal Ag at grain boundaries. However, a balance between doping and compositing in the same system $\left(\mathrm{Ca}_{2.7} \mathrm{Ag}_{0.3} \mathrm{Co}_{4} \mathrm{O}_{9} / \mathrm{Ag}-10 \mathrm{wt} \%\right)$ can lead to a promising $Z T$ of 0.5 at $1000 \mathrm{~K}$ [49]. Very recently, the highest $Z T$ of 0.74 has been achieved by Saini et al. at $800 \mathrm{~K}$ for Tb doped CCO-349 system. This is the highest $Z T$ ever reported for a polycrystalline oxide-based system [50].

\section{Effect of texturization}

On following the thermoforging process by Pravel et al. oncalcium cobalt oxide (CCO-349), a decrement in electrical resistivity was seen on increasing the applied pressure during the process which increases grain alignment. This study made way for further exploration of thermoforging and the influence of applied pressure on CCO-349 system [51]. On a comparative study of the effect of sintering technique on the thermoelectric performance, Liu et al. found that SPS leads to higher degree of grain orientation.

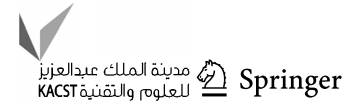


A sheet-like grains with 1-2 $\mu \mathrm{m}$ can be seen in both the cases due to the layered structure. However, a massive grain alignment and reduction in pore size can be seen in the case of SPS (Fig. 4b, c). This grain alignment not only leads to greater density of material (90\%-SPS as compared to $70 \%$-CS), but also holds responsible for the higher electrical conductivity. The measured electrical conductivity for the CS sample was $34 \mathrm{~S} / \mathrm{cm}$ at $973 \mathrm{~K}$, whereas SPS sample exhibited an electrical conductivity of $118 \mathrm{~S} /$ $\mathrm{cm}$. Although Seebeck coefficient variation was less, the higher difference in electrical conductivity leads to a highpower factor of $3.51 \times 10^{-4} \mathrm{~W} / \mathrm{m} / \mathrm{K}^{2}$ (SPS) as compared to $1.1551 \times 10^{-4} \mathrm{~W} / \mathrm{m} / \mathrm{K}^{2}(\mathrm{CS})$. These factors lead to $34.5 \%$ increment in $Z T$ of SPS sintered sample as compared to the CS sample [52]. Lin et al. performed a unique combination of SPS and dynamic forging technique leading improved texturization over the just SPS processed sample. It has been seen that this technique allows in lowering the resistivity of the sample without affecting much of Seebeck coefficient. To reduce thermal conductivity, lanthanum was doped in the CCO matrix. La leads to scattering of phonon as it is a heavy mass element leading to mass fluctuation in the matrix. Finally, ZT of 0.26 at $975 \mathrm{~K}$ was reported [53]. Neodymium substitution in the CCO matrix along with texturization efforts was done by Parvel et al. in 2007. Their results show that $\mathrm{Nd}$ increased the decomposition temperature of CCO. Also, thermoforging led to an increase in electrical conductivity of the sample by 2.5-fold. The decrease in carrier concentration with $\mathrm{Nb}$ substitution holds responsible for the improvement in Seebeck coefficient and thermopower [54]. A comparative study of conventional sintering, hot-pressing and spark plasma sintering, their texturization effects, and influence on thermoelectric parameters of CCO-349 were done by Kenfaui et al. The micrographs obtained for these methods revealed that there were a platelet formation and high degree of orientation in the case of the hot-pressed sample. The order of degree of orientation was: HP $>$ SPS $>$ CS.
Densification and texturing are found maximum in HP sample, and thus, resistivity is minimum $(6.1 \mathrm{~m} \Omega \mathrm{cm}$ at $300 \mathrm{~K})$, and Seebeck coefficient of $550 \mu \mathrm{W} / \mathrm{m} / \mathrm{K}^{2}$ at $850 \mathrm{~K}$ in the case of HP which was claimed to be one of the lowest resistivity and highest $S$ reported along the $a b$ plane [55]. Since the synthesized product was only $0.5 \mathrm{~mm}$ thick, module making would be a challenge. Hence, they stalked the multi-layers of CCO. Each layer of CCO was hot-pressed and polished. They were stalked together, hot-pressed again, and was cut along $a b$ and $c$ direction. Thermoelectric parameters measured parallel and perpendicular to $c$-axis show highly anisotropic nature of the sample. Finally, a ZT of 0.16 was realized along the ab plane [56]. To obtain a better power factor, optimizing stress while pressing multi-layers of CCO was later identified. Better power factor $\left(595 \mu \mathrm{W} / \mathrm{m} / \mathrm{K}^{2}\right)$ at higher stress level (30 $\mathrm{MPa})$ was realized by the team at $900 \mathrm{~K}$ along the ab plane $[57,58]$. The anisotropic resistivity behaviour was also explored later using a modified SPS technique called as SPT. In this technique, a pre-sintered pellet is kept in a die of bigger diameter in the second step for free deformation of pellet resulting in better texturization and platelet formation along the axis perpendicular to the pressing direction [59]. An improvement of 40-60\% $\left(170-180 \mu \mathrm{W} / \mathrm{m} / \mathrm{K}^{2}\right)$ in power factor was reported in 2016 as a result of microwave sintering. Microwave sintering resulted in an increase in density as well as the growth of elongated grains. The main reason for the enhancement is assigned to better electrical conductivity due to low porosity and texturing [60]. Strontium-doped CCO349 synthesised by hot-pressing exhibited higher electrical conductivity and lower Seebeck Coefficient. Resistivity close to those sintered by SPS method $(6 \mathrm{~m} \Omega \mathrm{cm})$ was obtained for the hot-pressed $\mathrm{Sr}$-doped $(6.5 \mathrm{~m} \Omega \mathrm{cm})$ sample at $1073 \mathrm{~K}$. Presence of $\mathrm{Sr}$ and $\mathrm{Ca}$ carbonate impurities on the surface of the sample along with grain alignment and good conductivity between the grains was attributed to be responsible for the improved electrical conductivity. Almost $20 \%$ higher PF (1.16 mW/
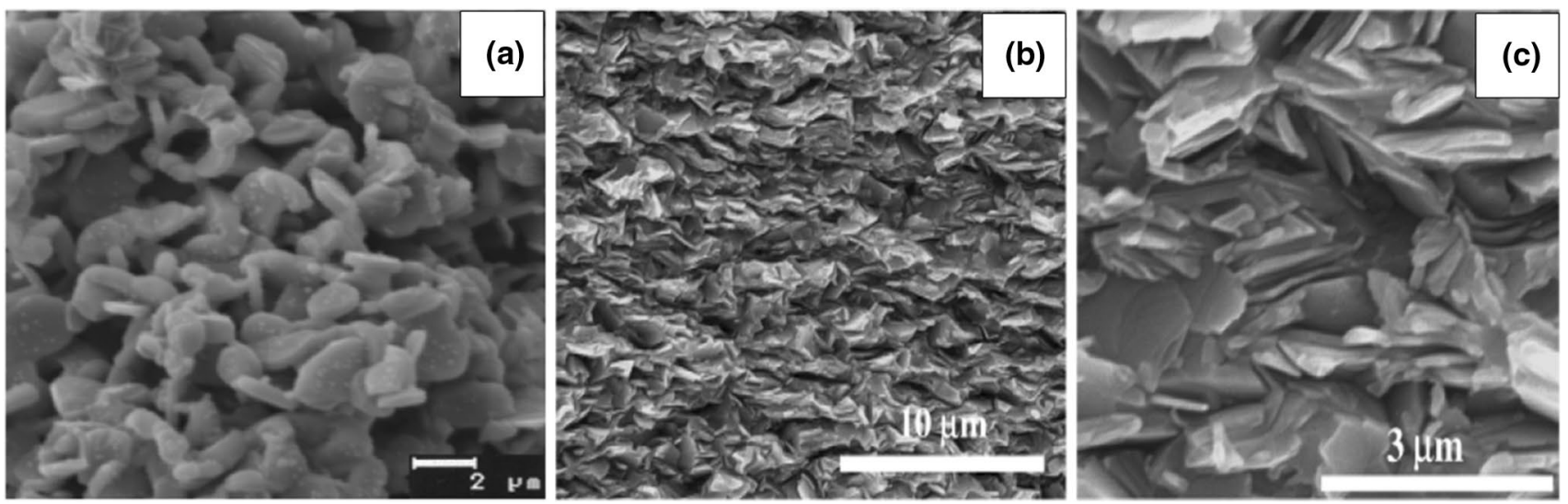

Fig. 4 Scanning electron microscopy of the fracture surface of CS (a) and SPS (b, c) materials

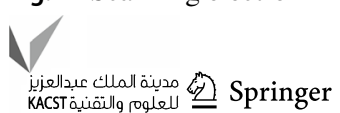


$\mathrm{K}^{2} \mathrm{~m}$ at $800^{\circ} \mathrm{C}$ ) were exhibited by the $\mathrm{Sr}$-doped samples as a result of high chemical pressure effects. Though there was significant improvement in electrical conductivity and power factor, $Z T$ was estimated to be 0.29 at $1073 \mathrm{~K}$ due to the high thermal conductivity $(4.4 \mathrm{~W} / \mathrm{K} \mathrm{m})$ [61]. $Z T$ as good as 0.36 at $1073 \mathrm{~K}$ were reported for $\mathrm{CCO}$ synthesised by calcining the nitrate hydrate precursors followed by cold pressing at $200 \mathrm{MPa}$ and sintering at $1173 \mathrm{~K}$. The porous structure clearly has lead to the reduction in thermal conductivity, which, for a highly dense sample, is a bane [62].

\section{$\mathrm{Na}_{x} \mathrm{CoO}_{2}$ (NCO)}

Great interest in misfit oxide-based thermoelectric materials was seen after the reporting very high thermopower of $\sim 100 \mu \mathrm{V} / \mathrm{K}$ by Terasaki et al. in 1997 for $\mathrm{Na}_{x} \mathrm{Co}_{2} \mathrm{O}_{4}$ [38]. Since the thermal conductivity exhibited by this lamellar based material was very low, it is considered to be fitting into the PGEC concept [63]. This oxide has a misfit doublelayer structure. One layer consists of the $\mathrm{CdI}_{2}$ type- $\mathrm{CoO}_{2}$ ions with edge-shared octahedra and $\mathrm{Na}$ ions stalked along $c$-axis on the other. While $\mathrm{CoO}_{2}$ layer acts as an electron reservoir and is responsible for electronic conductivity and thermopower, the $\mathrm{Na}^{+}$ion layer acts as an electron donor to the $\mathrm{CoO}_{2}$ layer and also holds responsible for reducing the thermal conductivity. The $\mathrm{Na}$ ions are intercalated between the $\mathrm{CoO}_{2}$ layers. The concentration of $\mathrm{Na}$ ions can be varied to manipulate the number of conduction electrons on the Co layers [64]. When $x=0$, the electrovalency of cobalt is +3 with 5 electrons occupying the ground state of the $t_{2} g$ band. And when $x=1$, the electrovalency of cobalt is +4 with a fully filled ground state $t_{2} g$ band [65]. They crystallize in the hexagonal structure with a space group of P63/mmc. In these family of oxides, since carrier density does not contribute to the power factor, tuning the same would leave no difference in the power factor. This class of materials was then found to be a promising candidate for high-temperature thermoelectrics as they exhibited good chemical stability and non-toxicity as compared to the other state-of-the-art materials like $\mathrm{Bi}_{3} \mathrm{Te}_{3}$ and $\mathrm{PbTe}$ [66]. Reports on polycrystalline $\mathrm{NaCo}_{2} \mathrm{O}_{4}$ with $\mathrm{Cu}$ doping at the Co site prepared by solid-state mixing method following hot pressing exhibited $Z T$ of 0.88 at $573 \mathrm{~K}$ for $\mathrm{Na}\left(\mathrm{Co}_{1-x} \mathrm{Cu}_{x}\right)_{2} \mathrm{O}_{4}(x=0.05)$. Though the thermal conductivity was $30 \%$ higher for the hot-pressed sample, a reduction in room temperature electrical resistivity from 2 to $1.1 \mathrm{~m} \Omega \mathrm{cm}$ (for NCO) as a result of hot pressing holds responsible for this improvement [67]. At low temperature, for sodium-deficient system, intercalated water results in superconducting transition. High Seebeck coefficient of $\sim 120 \mu \mathrm{V} / \mathrm{K}$ was reported by tailoring the $\mathrm{Na}$ $(x=0.15)$ stoichiometry in $\mathrm{Na}_{x} \mathrm{Co}_{2} \mathrm{O}_{4}$ [68]. Later on, adding metallic phase of ( $\mathrm{Ag}, \mathrm{Ti}, \mathrm{Rh}, \mathrm{Pd})$ into this system was tried to increase the electronic conductivity which was successful (not in the case of Ti) which also led to the Seebeck coefficient improvement and has been reported in $[69,70]$. Also, compositing $\mathrm{NCO}$ with $\mathrm{Ag}$ has led to enhancement of thermoelectric properties as seen in the work by Seetawan et al. A $2 \%$ doping at the cobalt site exhibited marginally lower resistivity $(66 \mu \Omega \mathrm{cm})$ over the complete temperature range as compared to the other compositions. A reduction in thermal conductivity was also observed mainly due to the singlephase NCO and due to the Ag presence, while the other compositions exhibited mixed phase. These factors combined to gather with a high power factor of $0.31 \mathrm{~mW} / \mathrm{m} / \mathrm{K}$ at $973 \mathrm{~K}$ leading to a $Z T$ of 0.124 at $973 \mathrm{~K}$ [71]. It has been seen that out of the transition-metal element addition $(\mathrm{Ni}$, $\mathrm{Fe}, \mathrm{Mn}$, and $\mathrm{Cu}$ ) into the cobalt site, only $\mathrm{Ni}$ and $\mathrm{Cu}$ were a promising dopant which rules out the possibility of other elements mentioned as an effective dopant for enhanced thermoelectric performance [72-74]. Addition of $\mathrm{Zn}$ has also led to enhancement in thermopower [75]. Krasutskaya et al. recently reported a $Z T$ of 1.57 at $1100 \mathrm{~K}$ for $x=0.89$ with a low thermal conductivity of $0.829 \mathrm{~mW} /\left(\mathrm{mK}^{2}\right)$ which is one of the highest $Z T$ reported for polycrystalline NCObased system [76]. By doping Co site with a minute fraction of $\mathrm{Fe}\left(\mathrm{Na}_{0.71} \mathrm{Co}_{0.95} \mathrm{Fe}_{0.05} \mathrm{O}_{2}\right)$ increased thermopower along the $a b$ plane to a greater extent and was reported recently by Richter et al.[77]. Behera et al. reported a low-temperature synthesis by nitrate-citrate combustion method which followed a low heat treatment strategy to obtain a $Z T$ of $\sim 0.01$ at $780 \mathrm{~K}$ for the $\mathrm{La}_{0.85} \mathrm{Na}_{0.15} \mathrm{CoO}_{3}$-based compound. The thermopower of this compound was found to be promising $(\sim 374 \mu \mathrm{V} / \mathrm{K}$ at $318 \mathrm{~K})$ due to strong electron correlation and degeneracy of $3 d$ orbitals of Co. However, thermal activation of holes due to $\mathrm{Na}$ (induces $p$-type conductivity) content at higher temperature reduces the thermopower [78].

\section{Effect of texturization}

The hydrothermal method was reported by Zhang et al. for the synthesis of NCO so as to develop materials with oriented growth which would add on to the texturing effects leading to improvements in thermoelectric performance. A strong anisotropic behaviour was exhibited by the HT sample as the grain boundary density was different along inplane and out-of-plane direction. However, the CSS sample failed to exhibit such a behaviour as a result of higher grain size and lower degree of grain alignment. Hence, in-plane electrical conductivity and Seebeck coefficient was much higher (Fig. 5a) along the complete temperature range as compared to the out-of-plane direction resulting in a drastic improvement in power factor of $\sim 0.43$ from $\sim 0.08 \mathrm{~mW} / \mathrm{m} \mathrm{K}^{2}$ at $993 \mathrm{~K}$ (Fig. 5b). Due to the high orientation degree of NCO-based materials, the grain boundary density is more along the out-of-plane direction. As a result of grain boundary scattering due to the high grain density, thermal 
(a)

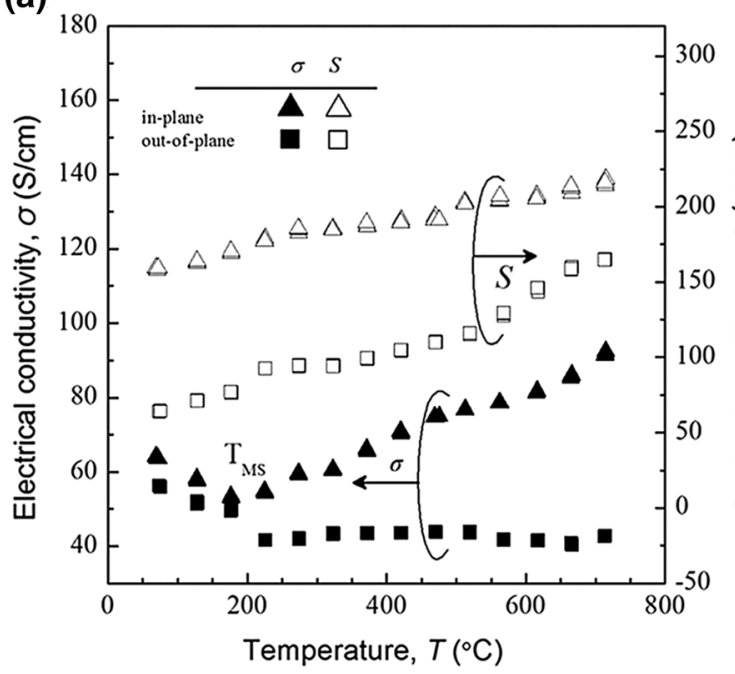

(c)

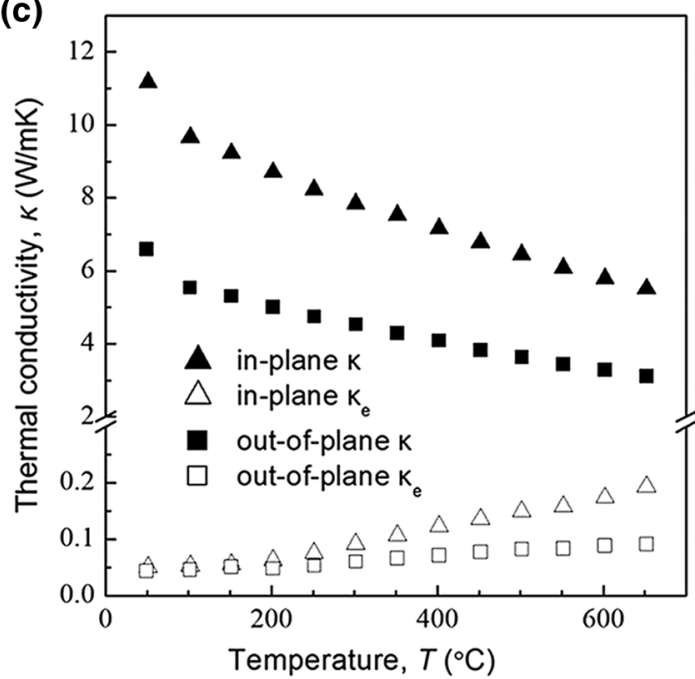

(b)

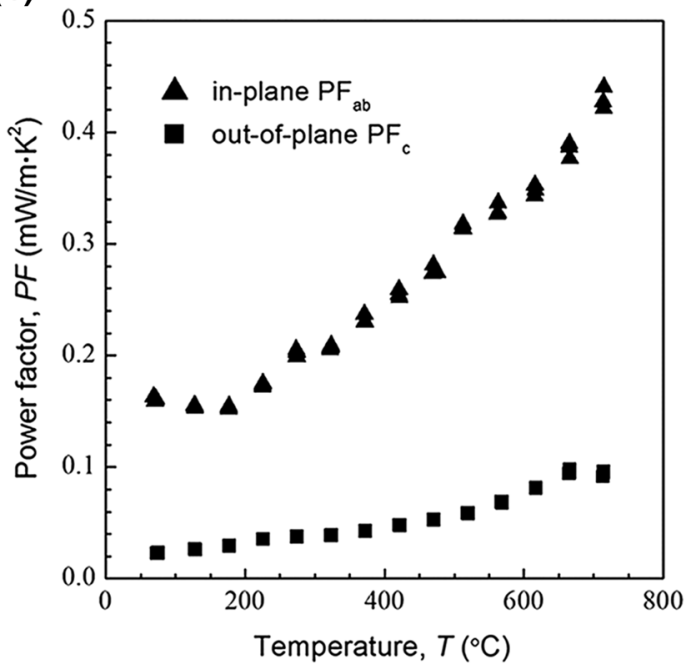

(d)

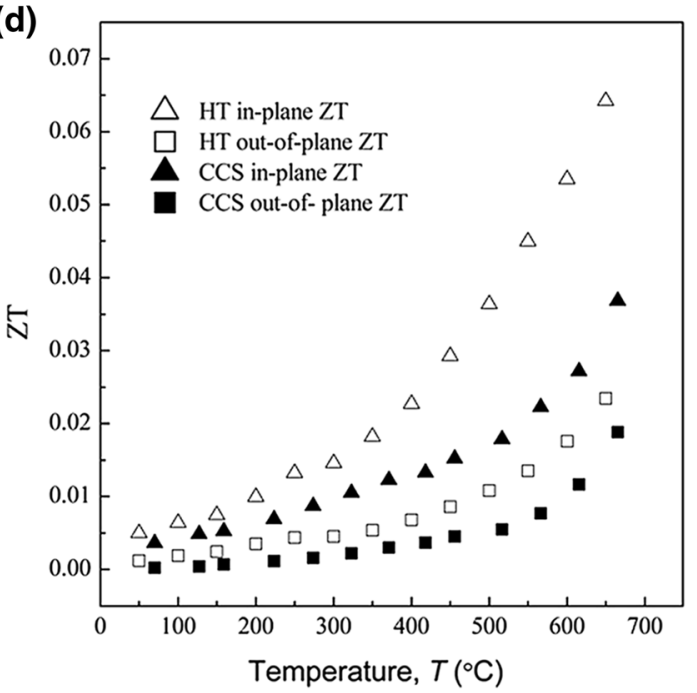

Fig. 5 Electrical conductivity (a), Seebeck coefficient (a), power factor (b), thermal conductivity (c), and thermoelectric figure of merit (d) variations with respect to temperature for the NCO-based material under two pressing directions

conductivity decreases (also leads to reduction in electrical conductivity) (Fig. 5c). However, NCO prepared by HT and cut along the in-plane direction exhibits maximum $Z T$ of 0.064 at $923 \mathrm{~K}$ (Fig. 5d) due to the high power factor and low thermal conductivity $(\sim 5.2 \mathrm{~W} / \mathrm{mK}$ at $923 \mathrm{~K})$ [79]. The transport properties of layered cobaltates are highly anisotropic due to the layered structure. Hence, texturization finds potential in the improvement of their properties as it would lead to a higher degree of grain alignment, thereby increasing the electrical conductivity.

\section{Zno}

$\mathrm{ZnO}$ is an $n$-type wide band-gap semiconductor having bandgap of $3.37 \mathrm{eV}$, and has been used extensively for various applications such as UV-light emitters, solar cells, flat panel display, light-emitting devices, piezoelectric transducers, brake linings, cosmetics, dental cements, lubricants, paints, phosphors, and other products due to its low cost, abundance, non-toxicity, and thermal/chemical stability [80-82]. Wurtzite structure is the most common structure exhibited by $\mathrm{ZnO}$ with a space group of $\mathrm{P}_{3} \mathrm{mc}$. However, zinc blend structure with a space group of $\mathrm{Fm} 3 \mathrm{~m}$ is also seen under pressure. A typical wurtzite crystal structure is shown in Fig. 6. Here, the brown sphere indicates zinc atom and blue indicates an oxygen atom.

Elements such as Aluminium, Indium, Gallium, etc. are doped in the $\mathrm{ZnO}$ matrix to optimise the wide bandgap of $\mathrm{ZnO}$ for applications in the field of solar cells, thermoelectric, and optoelectronic applications [83-85]. A high carrier 


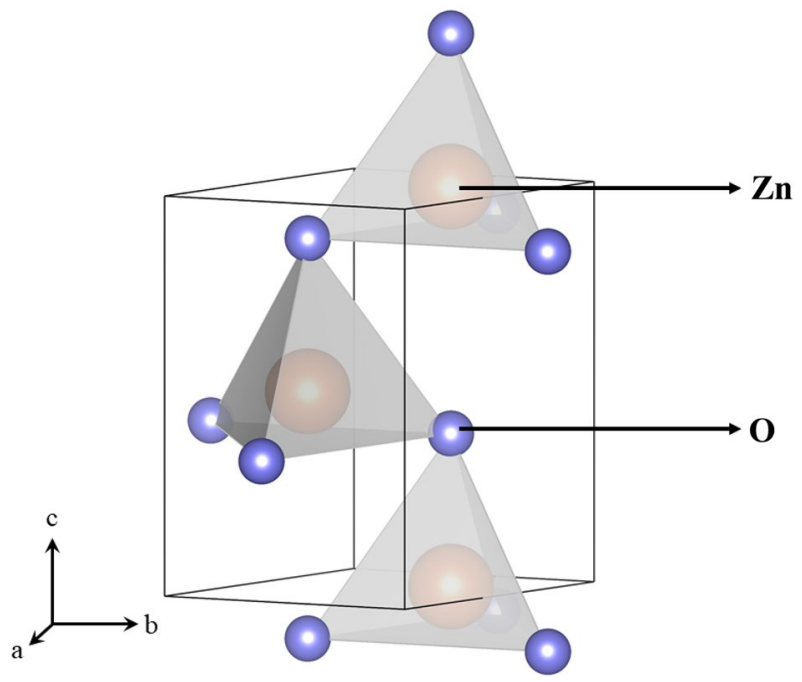

Fig. 6 Crystal structure of wurtzite-type $\mathrm{ZnO}$ simulated with VESTA

concentration $\left(>10^{20} \mathrm{~cm}^{-3}\right)$ is exhibited by the group III elements which makes them ideal dopants. Out of the group III elements, Al has been identified to be the most abundant and also is a shallow donor making it one of the most suitable dopants to increase the n-type character [80]. $\mathrm{ZnO}$ exhibits a harmonically vibrating lattice as a result of the ionic and covalent nature leading to high thermal conductivity $\left(\sim 40 \mathrm{~W} / \mathrm{m} / \mathrm{K}^{1}\right)$. M. Ohtaki in 1996 identified $\mathrm{ZnO}$ to be a potential thermoelectric material exhibiting a PF of $8-15 \times 10^{-4} \mathrm{~W} / \mathrm{m} \mathrm{K}^{2}$ for aluminium-doped zinc oxide and leading to $Z T$ of 0.3 at $1273 \mathrm{~K}$. Though they possess high thermal conductivity due to the ionic character of $\mathrm{ZnO}$, due to higher carrier mobility and carrier concentration, the electrical conductivity shot up without much decrement in thermopower [86]. Observation of enhancement in thermopower of Al-doped ZnO-based systems was reported by Ohtaki as a result of phonon scattering by the nanovoids-leading to suppressed thermal conductivity [87] to give a $Z T$ of 0.55 to 0.57 at $1273 \mathrm{~K}$, thermionic effects due to the nanovoids and suspected carrier energy filtering by the nanovoids to deliver a $Z T$ of up to 0.6 at $1250 \mathrm{~K}$ [88]. Later, dually doped $\mathrm{ZnO}(\mathrm{Ga}, \mathrm{Al})$ set a benchmark by exhibiting a $Z T$ of 0.65 at $1247 \mathrm{~K}$ where $\mathrm{Ga}$ acted as the scattering centres to reduce thermal conductivity, whereas $\mathrm{Al}$ acted as an agent to increase the carrier mobility which increases the electrical conductivity [89]. More recently, Jood et.al reported a $Z T$ of $\sim 0.44$ for $1000 \mathrm{k}$ that reached thermal conductivity of $\sim 2 \mathrm{~W} / \mathrm{mK}$. However, further improvements are necessary to obtain better $Z T$ values [90]. Very recently, Zhakharchuk et al. reported a slightly improved $Z T$ of close to 0.12 for $\mathrm{Zn}_{0.994} \mathrm{Al}_{0.003} \mathrm{Zr}_{0.003} \mathrm{O}$ at $1200 \mathrm{~K}$. While new scattering interfaces and suppression of thermal conductivity were due to zirconia, enhancement of electrical transport properties mainly led to this enhancement [91]. Recently, $\mathrm{Cd}_{1-x} \mathrm{Zn}_{x} \mathrm{O}$ were explored and was seen to exhibit one of the highest $Z T$ of 0.52 at $1000 \mathrm{~K}$ for any $n$-type oxide-based material with $1 \%$ doping. The phonon scattering from multiple scale scattering sources such as point defects, grain boundary, $\mathrm{ZnO}$ nanoprecipitates, and micropores leads to very low thermal conductivity and can be attributed to as the main reason for the high $Z T$ reported [92]. Further optimisation of dopant and size of nanoparticle could also lead way for better $Z T$ [93]. Lately, $\mathrm{Al}$ and $\mathrm{Zr}$ codoping have been found to be a promising combination in the $\mathrm{ZnO}$ matrix which would suppress the thermal conductivity and boost electrical conductivity. $\mathrm{Zn}_{0.997} \mathrm{Al}_{0.002} \mathrm{Zr}_{0.005} \mathrm{O}$ showed a $Z T$ of 0.12 at $1173 \mathrm{~K}$. This mixed combination was seen to exhibit the lowest thermal conductivity and better $Z T$ than the individual-doping compositions [94]. Dy doping has been tried in the $\mathrm{ZnO}$ matrix by Anju et al. Since Dy possess higher ionic radii and since they produce localised magnetic moment due to unpaired electron, it can effectively act as the phonon scatterer and lead to reduction in thermal conductivity. On the addition of $1 \%$ Dy atoms, thermal conductivity was reduced to up to $2 \mathrm{~W} / \mathrm{mK}$ at $900 \mathrm{~K}$. Also, since Dy leads to remarkable increase in electrical conductivity, i.e., up to 1000 times as compared to pristine $\mathrm{ZnO}$ at $373 \mathrm{~K}$. These factors lead to an improved $Z T$ of 0.11 at $923 \mathrm{~K}$ [95].

\section{Effect of texturization}

The thermoelectric properties exhibited by pure and doped zinc oxide are discussed above. However, it is known that texturization could lead to an improvement in the thermoelectric parameters. Han et al. synthesised aluminium-doped $\mathrm{ZnO}$ by various methods to obtain rods, platelets, and nanoparticles. SPS technique was used for sintering and induce texturing in the sample (Fig. 7). The relation between various morphologies on the thermoelectric parameters after texturing was then explored [96].

It was seen that the rods exhibited maximum electrical conductivity (Fig. 8a) and carrier mobility (Fig. 8b). One of the reasons for this improvement is the aligning of rods along the perpendicular direction leading to a reduction in number of grain boundary, thereby reducing the scattering of charge carriers, hence proving that microstructure and morphology plays an important role. The parallelly cut rods and platelets exhibited least thermal conductivity which again is a proof of anisotropic behaviour (Fig. 8c). Parallelly cut samples exhibit maximum grain boundaries leading to maximum phonon scattering. However, nanoparticles exhibit the least thermal conductivity due to impurity scattering and grain boundary scattering. Though nanoparticles exhibit poor electrical conductivity, carrier mobility, and carrier concentration as compared to the other morphologies, since they exhibit the least thermal conductivity, and

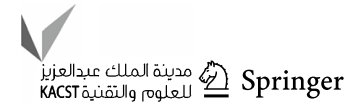


Fig. 7 Illustration of the consolidation process for a rods, $\mathbf{b}$ platelets, and $\mathbf{c}$ particles which were cut parallel and perpendicular to the pressing direction for measurements
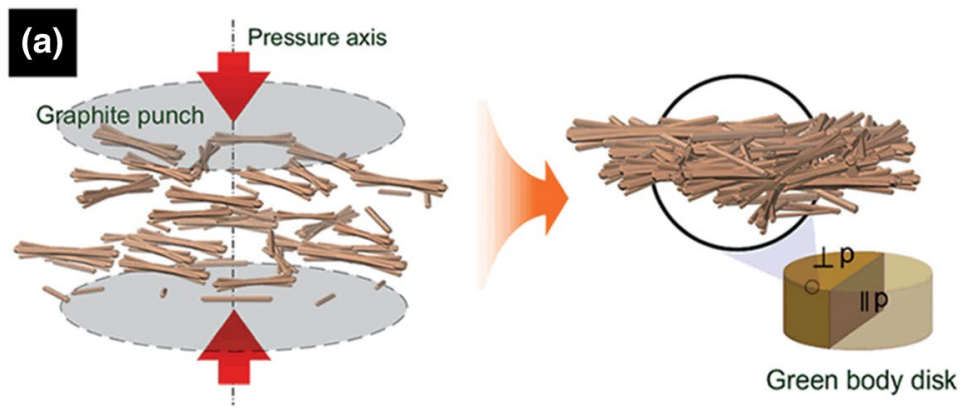

Cutting \& characterization
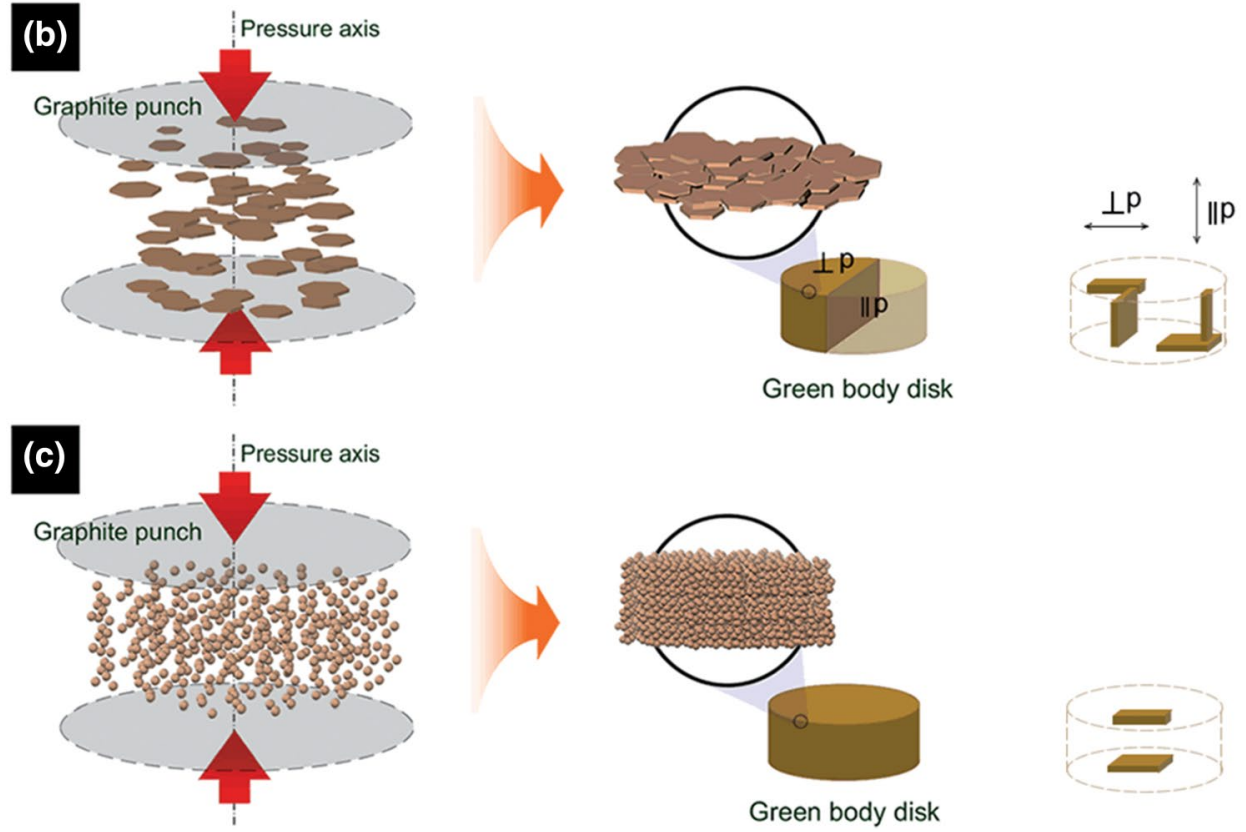

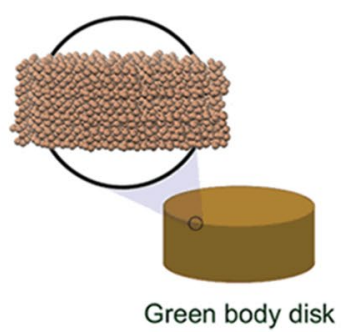

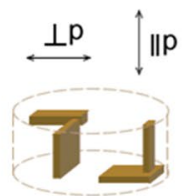

Green body disk

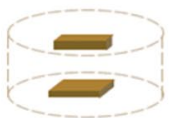

the $Z T$ exhibited by nanoparticles is maximum $(Z T=0.30$ at 1223 K) (Fig. 8d) [96].

\section{$\ln _{2} \mathrm{O}_{3}$ based ceramics}

Homologous $\mathrm{In}_{2} \mathrm{O}_{3}-\mathrm{ZnO}$-based system has been widely studied for their thermoelectric performance as they possess excellent structural and chemical stability even at higher temperature [97]. They are indexed by rhombohedral symmetry. Homologous $(\mathrm{ZnO})_{\mathrm{k}} \cdot \mathrm{In}_{2} \mathrm{O}_{3}$ belong to the space group of $R 3 m$ for odd values of $k$ and $\mathrm{P} 63 / \mathrm{mmc}$ for even values of $k$ [98]. Particularly, the wide bandgap exhibited by these compounds leads to better thermoelectric parameters as they would resist the thermal excitation of electrons at higher temperature [99]. They exhibit a layered structure with alternating layers of edge-sharing In-O octahedral layers and In-Zn-O layers arrange in a zigzag manner [100]. The $n$-type conductivity exhibited by this compound is dominant through hexagonal lattice than across the $a b$ plane as the main in-plane conducting path is In-O layer and $\mathrm{In}-\mathrm{Zn}-\mathrm{O}$ being the out-of-plane conducting path [97, 99]. Local charge deficiencies in the crystal are created as a consequence of $\mathrm{Zn}$ vacancies created as they are the preferential site for incorporation of $\mathrm{In}^{3+}$ ions. Their ordering further leads to $(\mathrm{ZnO})_{\mathrm{k}}$. $\mathrm{In}_{2} \mathrm{O}_{3}$ (IZO)-type phases [101]. It was identified by Ohta et al. in 1996 that such series could be potential thermoelectric material. They reported that $Z T$ would increase with increase in the concentration of $\mathrm{ZnO}$ (i.e., $k=3,5,7$ and 9 with maximum $Z T$ at $k=9$ ). $Z T$ values of 0.11 at $900 \mathrm{~K}$ have been reported by Bernik et al. for $k=5$ as a consequence of sintering, pre-reacted mixture, and raw mixture in 1:1 ratio leading to lower thermal conductivity [102].

The representation of the crystal structure of $\operatorname{In}_{2} \mathrm{O}_{3}$, $\mathrm{ZnO}$, and $(\mathrm{ZnO})_{5} \mathrm{In}_{2} \mathrm{O}_{3}$ is given in Fig. 9. The brown sphere indicates $\mathrm{Zn}$ atoms, light blue indicates oxygen atoms, and the periwinkle blue indicates In atom. The introduction of point defects in $\mathrm{In}_{2} \mathrm{O}_{3}$ results in a glass-like thermal conductivity. The lattice thermal conductivity could be reduced by $60 \%$ and extraordinary low lattice thermal conductivity of $1.2 \mathrm{~W} / \mathrm{mK}$ at $973 \mathrm{~K}$ was also reported. However, point defect engineering by co-doping $\mathrm{Zn}$ and $\mathrm{Ce}$ in the $\mathrm{In}_{2} \mathrm{O}_{3}$ system $\left(\mathrm{In}_{2-2 x} \mathrm{Zn}_{x} \mathrm{Ce}_{x} \mathrm{O}_{3}\right)$ leads to a much better thermoelectric parameter $(Z T=0.44$ for $x=0.12)$. 
(a)

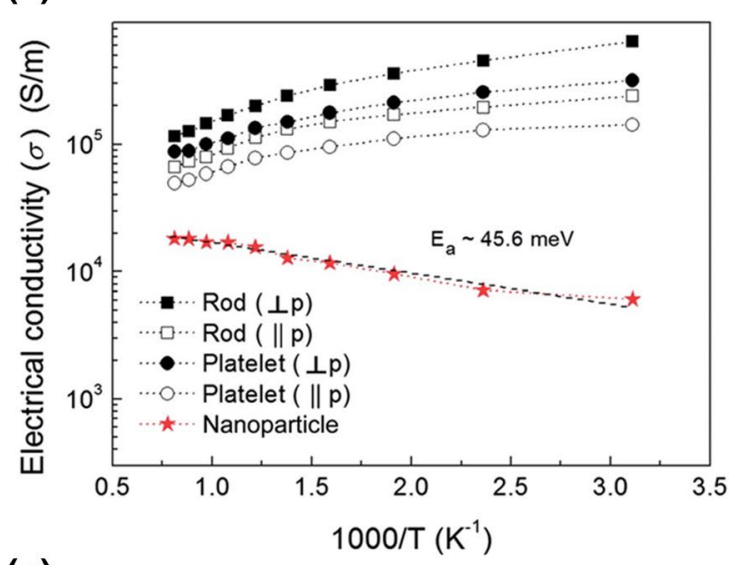

(c)

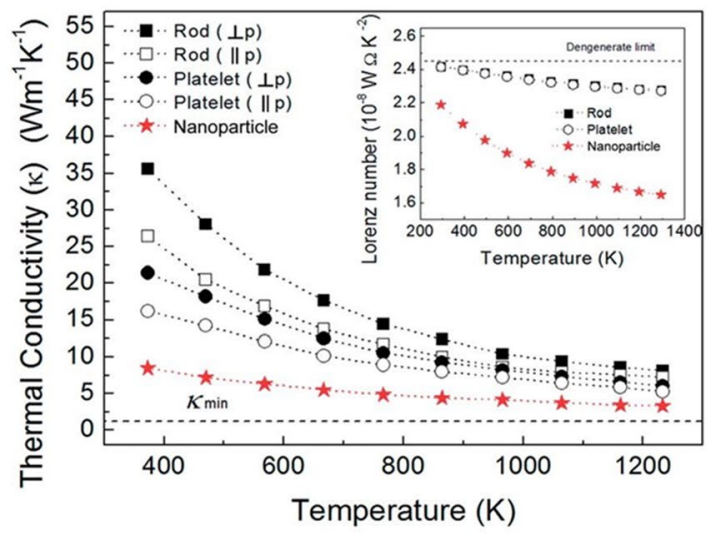

(b)
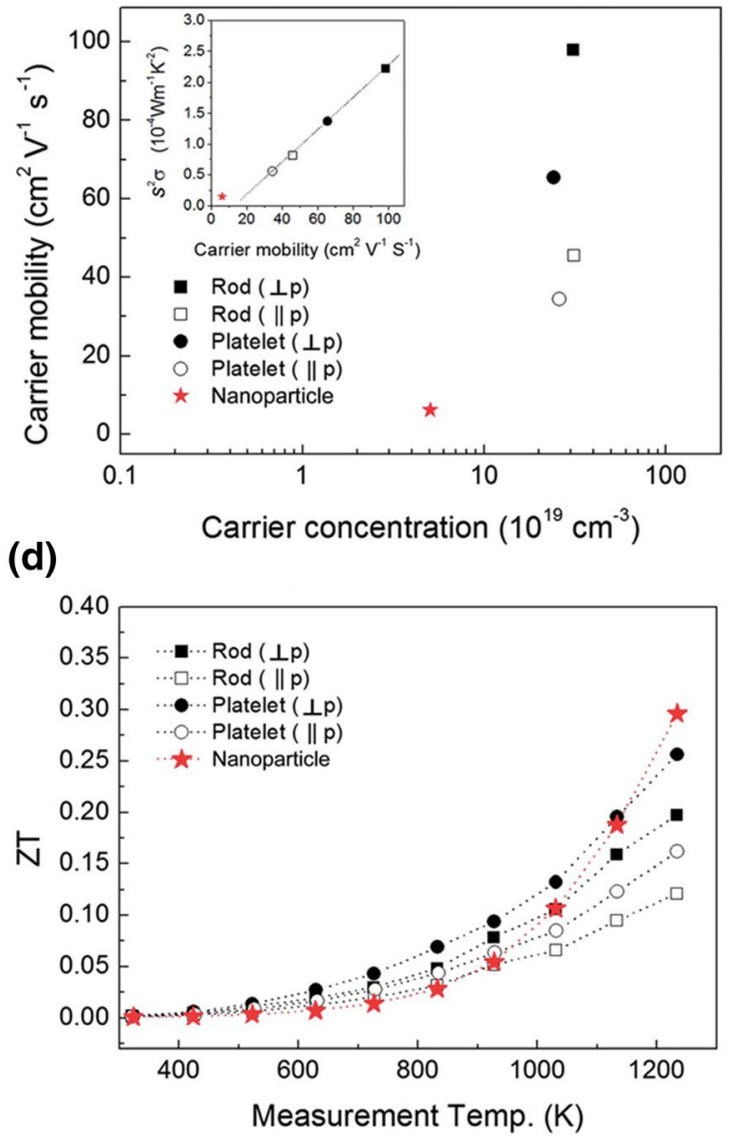

Fig. 8 Electrical conductivity (a), carrier mobility (b), thermal conductivity (c), and thermoelectric figure of merit $(\mathbf{d})$ of $\mathrm{Zn}_{1-x} \mathrm{Al}_{x} \mathrm{O}(x=0.02)$ measured for samples cut parallel and perpendicular to pressing direction

Various other elements were doped in $\mathrm{ZnO}$ for thermoelectric applications such as $\mathrm{Ca}, \mathrm{In}, \mathrm{Ni}, \mathrm{Nb}, \mathrm{Dy}, \mathrm{Yb}, \mathrm{Y}$, and Gd which have led to a decrease in thermal conductivity. It was identified that $\mathrm{Dy}, \mathrm{Yb}$, and $\mathrm{Gd}$ are the most suitable dopants, since they possess higher mean atomic mass leading to a low heat capacity which is directly related to thermal conductivity. Kosir et al. studied this system for varying $\mathrm{k}$ values of 5,11 , and 18 . It was identified that total thermal conductivity was minimum for least $k$ value. Similarly, promising electrical conductivity was seen in the case of $k=5$, while 11 and 18 exhibited less electrical conductivity. The reason for this trend was attributed to the $\mathrm{In}_{\mathrm{Zn}}$ planar defect density. Higher the defect density, lower was the thermal conductivity and better electrical conductivity. It was also seen that sintering the composite at $1773 \mathrm{~K}(Z T \sim 0.125)$ resulted in a better $Z T$ than for the material sintered at $1573 \mathrm{~K}(Z T \sim 0.11)$ at $973 \mathrm{~K} \mathrm{[103].}$ Later, in the same year, they reported that the addition of $\mathrm{Al}$ into homologous IZO with $k=5$ results in a slight increment in $Z T$. However, the improvement was very little $(Z T \sim 0.13)$ which was for the composition with $x=0.01$ in $(\mathrm{ZnO})_{k}\left(\operatorname{In}_{1-x} \mathrm{Al}{ }_{x}\right) \mathrm{O}$ and $k=5$ which was because of the increment in carrier mobility due to $\mathrm{Al}$ and reduction in thermal conductivity [104].

Berardan et al. later explored the potential of Germanium doped $\operatorname{In}_{2} \mathrm{O}_{3}\left(\operatorname{In}_{2-x} \mathrm{Ge}_{x} \mathrm{O}_{3}\right)$ as a thermoelectric material. It was observed that a decrease of fivefold in resistivity of the sample was seen on the addition of just $x=0.002$ of $\mathrm{Ge}$ in the $\operatorname{In}_{2} \mathrm{O}_{3}$ matrix. The resistivity of the sample further decreased on addition of more $\mathrm{Ge}$ which resulted in a decrease in resistivity from $\sim 25 \mathrm{~m} \Omega \mathrm{cm}$ to $\sim 1.5 \mathrm{~m} \Omega \mathrm{cm}$ at $x=0.015$ measured at $1000 \mathrm{~K}$. It was also pointed out that $\mathrm{Ge}$ addition selectively reduces thermal conductivity (3-0.6 W/mK) without affecting charge carrier mobility altogether giving rise to a $Z T$ of 0.45 at $1273 \mathrm{~K}$ [105]. Since In is a rare element, reducing the In content is of importance. Bhame et al. were successful in reducing the indium content and still obtain thermoelectric parameters comparable to the doped $\mathrm{In}_{2} \mathrm{O}_{3}$ system. The fluorite-type structure of $\mathrm{Ga}_{3-x} \mathrm{In}_{5+x} \mathrm{Sn}_{2} \mathrm{O}_{16}$ resulted in interesting thermoelectric performance [106]. Zhou et al. observed that in the In-Sn-O system, a lower density of the final sample reduces electrical

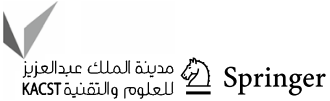




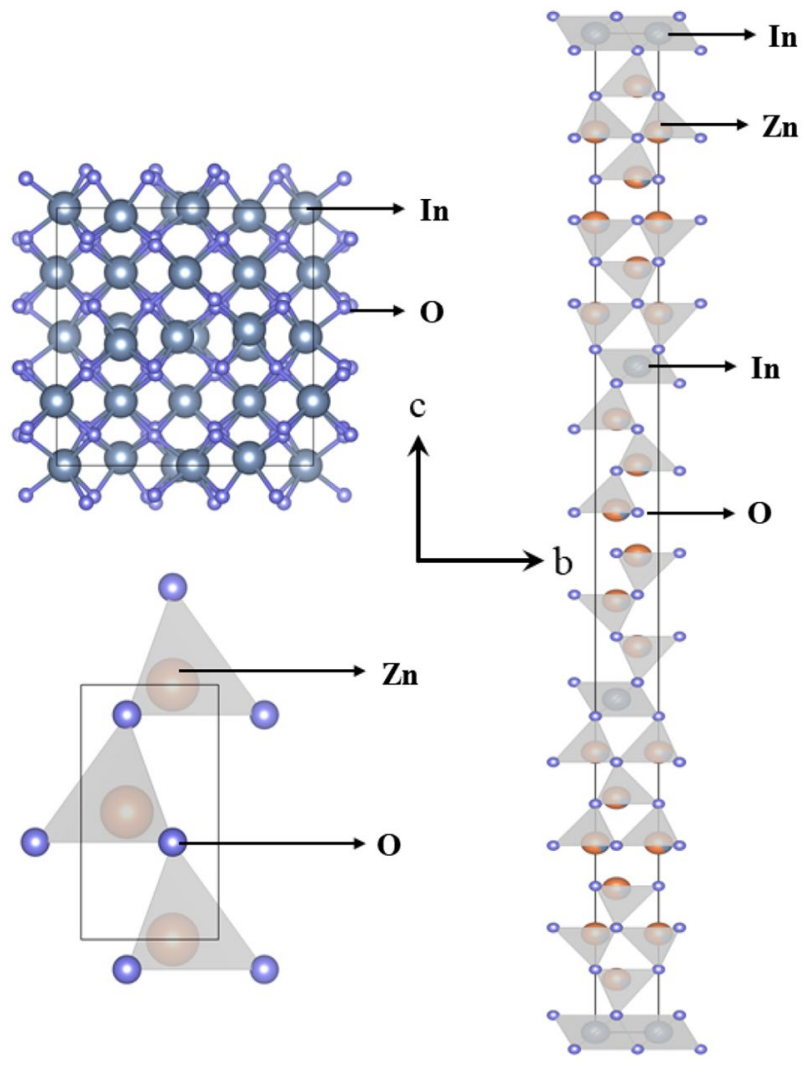

Fig. 9 Schematic representation of crystal structure for parent oxides $\left(\mathrm{In}_{2} \mathrm{O}_{3}, \mathrm{ZnO}\right)$ and $(\mathrm{ZnO})_{5} \mathrm{In}_{2} \mathrm{O}_{3}$

conductivity. However, reactive sintering with gallium addition seemed to overcome this by densifying the sample further. It resulted in an increase in density to up to $90 \%$ of bulk density. $\mathrm{Ga}_{2} \mathrm{In}_{6} \mathrm{Sn}_{2} \mathrm{O}_{16}$ and $\mathrm{SnO}_{2}$ secondary phases were seen as a result of reactive sintering of the precursors. However, a large number of localized grain boundaries among secondary phases result in grain growth and increase the density. Though thermal conductivity increases with $\mathrm{Ga}$ addition, finally with a minute addition of $\mathrm{Ga}, Z T$ of $\sim 0.23$ was reported at $1000 \mathrm{~K}$ [107]. Combe et al. reported a $Z T$ of 0.3 at $1000 \mathrm{~K}$ for the $\mathrm{Ge}$ doped $\operatorname{In}_{2} \mathrm{O}_{3}$ system. They pointed out a decrease in thermal conductivity at high temperature after the solubility limit of $\mathrm{Ge}$ in the $\operatorname{In}_{2} \mathrm{O}_{3}$ system (less than 0.5 at $\%)$. The decrease in thermal conductivity was attributed to the homogeneously distributed insulating secondary phases of $\mathrm{In}_{2} \mathrm{Ge}_{2} \mathrm{O}_{7}$ observed after the solubility limit. Though electrical resistivity increased after the solubility limit, the total effect contributed to an enhanced $Z T$ [108].

\section{Effect of texturization}

Among the homologous IZO series, $k=5$ resulted in maximum $Z T$ and has been mentioned already. Texturization efforts were made on this composition to obtain $Z T$ of 0.18 at $1027 \mathrm{~K}$. The textured samples were obtained by Tani et al. with the help of RTGG method (Fig. 10). A high degree of anisotropy was seen in the electrical conductivity measurements. The samples cut perpendicular to the casting direction ( $c$ plane) exhibited less conductivity as compared to the sample cut parallel showing the effect of misalignment distribution of grains. Greater number of grain boundaries is seen in the case of perpendicularly cut sample, whereas long grains and fewer grain boundaries in parallelly cut samples lead to higher electrical conductivity. However, a huge difference between the textured $(\sim 2 \mathrm{~W} / \mathrm{mK})$ and non-textured $(\sim 5 \mathrm{~W} / \mathrm{mK})$ sample is shown in the case of thermal conductivity due to the high density exhibited by them regardless of the direction in which the sample is cut [98].

Isobe et al. synthesised Y-doped IZO5 $\left(\left((\mathrm{ZnO})_{5}\right.\right.$ $\left.\mathrm{In}_{0.97} \mathrm{Y}_{0.03}\right)_{2} \mathrm{O}_{3}$ ) by RTGG method to obtain textured samples. SEM images revealed longer grains and grain orientation for the perpendicularly cut sample as compared to the parallel one. Although the sintered specimens exhibited less density, the electrical conductivity was seen to be greater for the textured samples. Textured samples exhibited half the thermal conductivity exhibited by the non-textured specimens. The thermal conductivity exhibited by Y-doped nontextured (impurity scattering) specimen was also exhibited by the textured undoped samples (scattering due to pores). However, combining both the effects textured Y-doped IZO samples exhibited the maximum $Z T$ of 0.33 at $1073 \mathrm{~K}$. Such a $Z T$ was possible due to the samples retaining high electrical conductivity in spite of low density [109].

Kaga et al. reported a $Z T$ of 0.31 for textured Ca-doped IZO as compared to the non-textured sample that showed a $Z T$ of 0.23 at $1053 \mathrm{~K}$. RTGG technique was followed for texturization. RTGG method introduces bigger grains and higher degree of alignment than the reference sample. Electrical conductivity measurements show that there was a certain degree of anisotropy present in the sample. Samples cut parallel to $a b$-axis exhibited better electronic conductivity. Though at temperatures close to room temperature, the thermal conductivity is less for $c$-plane measurements, at high-temperature both exhibited almost similar thermal conductivity leading to $Z T$ of 0.31 [110].

\section{BiCuSeO}

$\mathrm{BiCuSeO}$ is an interesting class of mixed anionic compounds made of oxide-based chalcogenide atoms. The oxide and chalcogenide atoms are indirectly bonded through the cationic atoms. This leads to an alternating insulating and conducting fluorite-like layers of oxide $\left(\mathrm{Bi}_{2} \mathrm{O}_{2}\right)^{2+}$ and chalcogen $\left(\mathrm{Cu}_{2} \mathrm{Se}_{2}\right)^{2-}$, respectively, along the $c$-axis. This naturally leads to better carrier mobility along with the $a, b$ planes than along the $c$ plane resulting in anisotropy. These features make them a suitable thermoelectric material and were first 
Fig. 10 The methodology followed for the synthesis of textured IZO (a). b SEM of the parallelly cut, $\mathbf{c}$ perpendicularly cut sample processed by RTGG method, and $\mathbf{d}$ reference sample

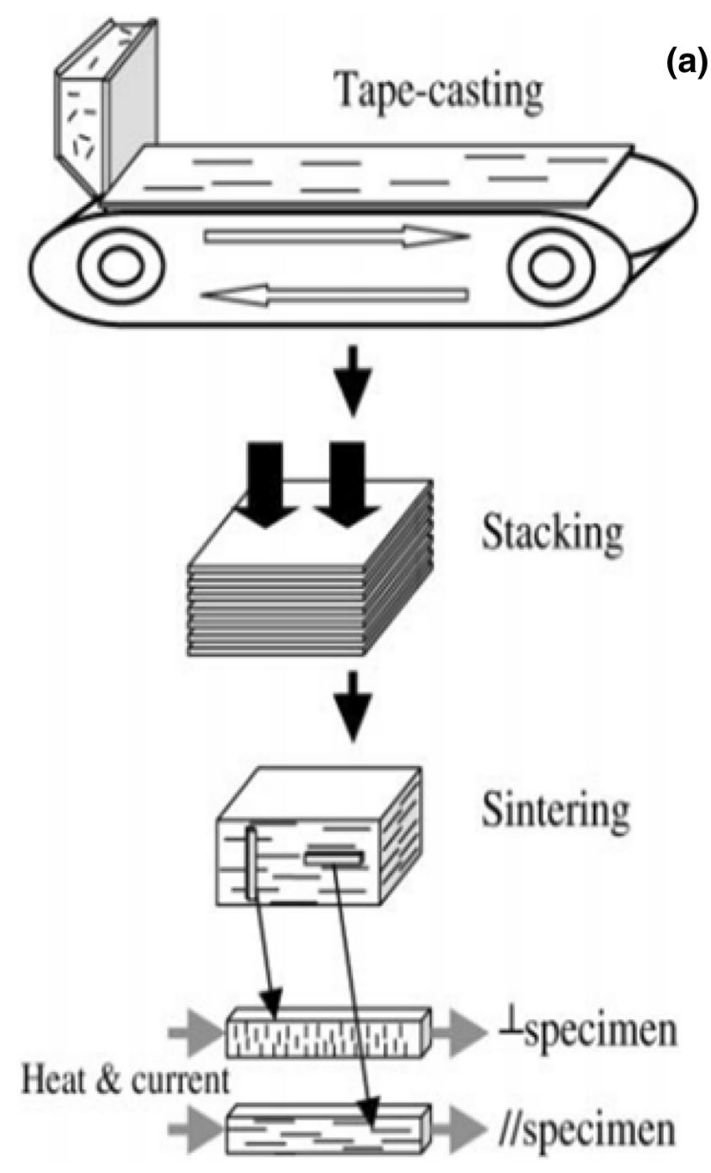

(a)
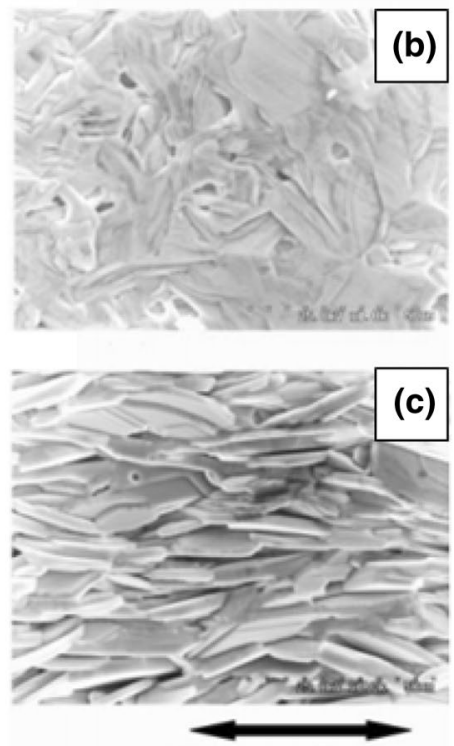

Casting direction

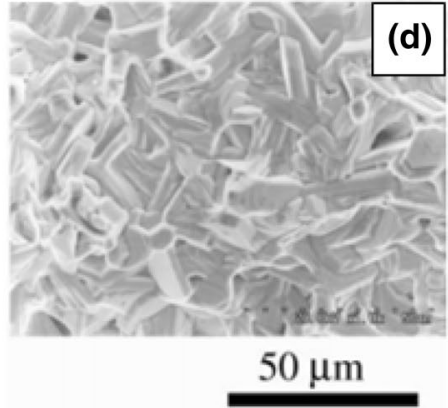

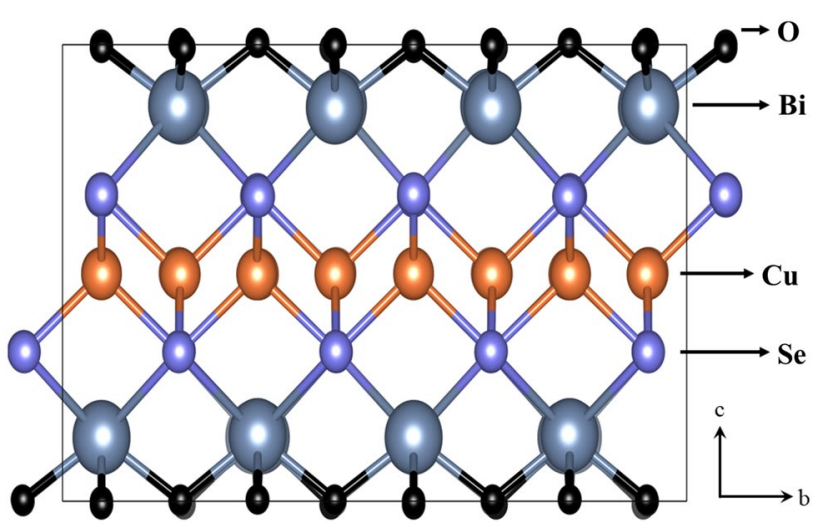

Fig. 11 Crystal structure of $\mathrm{BiCuSeO}$ generated using VASP

reported in 2010 with Sr doping [11, 111, 112]. They usually crystallize in the tetragonal system with $a=b=3.9273$ and $c=8.9293$ as unit cell dimensions and belongs to the space group of $\mathrm{P} 4 / \mathrm{nmm}$. The figure shows the crystal structure of $\mathrm{BiCuSeO}$ exhibiting a tetrahedral symmetry [113].

Figure 11 represents the $\mathrm{BiCuSeO}$ crystal structure. The orange sphere represents a $\mathrm{Cu}$ atom, blue sphere represents
Se atom, periwinkle blue sphere represents the $\mathrm{Bi}$ atom, and black sphere represents the oxygen atoms. At room temperature, their carrier concentration is reported to be $10^{18} \mathrm{~cm}^{-3}$ and carrier mobility is $22 / \mathrm{cm}^{2} / \mathrm{V} / \mathrm{s}$ [114]. A huge leap in the electrical conductivity for this class of material was achieved in 2010 when $\mathrm{Sr}$ was doped with $\mathrm{BiCuSeO}$. The electrical conductivity increased from $470 \mathrm{~S} / \mathrm{m}$ to $4.8 \times 10^{4} \mathrm{~S} / \mathrm{m}$ at $293 \mathrm{~K}$ on $\mathrm{Sr}$ substitution at the Bi site by a proportion of just 0.15 at $\%$. This drastic increase was assigned to be responsible due to the carriers that are induced in the $\left(\mathrm{Bi}_{2} \mathrm{O}_{2}\right)^{2+}$ layer that acts as the charge reservoir by partially substituting $\mathrm{Bi}^{3+}$ with $\mathrm{Sr}^{2+}$ and transferring it to the conducting $\left(\mathrm{Cu}_{2} \mathrm{Se}_{2}\right)^{2-}$ layer. As the thermal conductivity of this material is by default very low $(\sim 0.65 \mathrm{~W} / \mathrm{mK}$ at $873 \mathrm{~K})$ along with increased electrical conductivity and Seebeck coefficient $(\sim 225 \mu \mathrm{V} / \mathrm{K})$ leads to a $Z T$ of 0.76 at $873 \mathrm{~K}$ [115]. Very soon on realizing the potential of oxychalcogenides, especially $\mathrm{BiCuSeO}, \mathrm{Ca}$ doping at the $\mathrm{Bi}$ site resulted in a reduction of thermal conductivity and improved power factor as a result of improvised electrical conductivity as compared to the undoped sample. The replacement of $\mathrm{Bi}$ with $\mathrm{Ca}$ lead to an increase in the hole concentration hence transferring charge carriers from charge reservoir $\left(\mathrm{Bi}_{2} \mathrm{O}_{2}\right)^{2+}$ 
layer to the conducting $\left(\mathrm{Cu}_{2} \mathrm{Se}_{2}\right)^{2-}$ layer. The overall $Z T$ for $\mathrm{Bi}_{0.0925} \mathrm{Ca}_{0.075} \mathrm{CuSeO}$ is reported to be 0.9 at $923 \mathrm{~K}$ [116]. However, in 2014, Pei et al. reported the highest $Z T$ of all times till the date for undoped BCSO exhibiting a $Z T$ of 1.4 at $923 \mathrm{~K}$. Such a huge leap from the previously reported $Z T$ for pristine sample ( 0.70 at $773 \mathrm{~K}$ as in [117]) was mainly because of the improvement of power factor (Fig. 12c) due to modulation doping strategy (MD). MD strategy has been used to increase the carrier mobility. They could improve mobility by twofold without deteriorating the carrier concentration. This leads to a high electrical conductivity without and resulted in a very high $\mathrm{PF}$ of $10 \mu \mathrm{W} / \mathrm{cm} / \mathrm{K}^{2}$ at $923 \mathrm{~K}$. However, MD had no much influence on the Seebeck coefficient. These factors along with a decrease in $\mathrm{K}_{\text {lat }}(\sim 0.25 \mathrm{~W} /$ $\mathrm{mK}$ ) lead to $Z T$ of 1.4 at $923 \mathrm{~K}$ (Fig. 12f) [118].

Previous reports show that single-element doping has led to the improvement in either electrical conductivity or thermal conductivity. An improvement in both has been observed, but very moderate. To combine both the effects, i.e., reduction in thermal conductivity and increase in electrical conductivity, Liu et al. carried out dual-doping technique, whereby $\mathrm{Pb}$ acted as agent for the improvement in
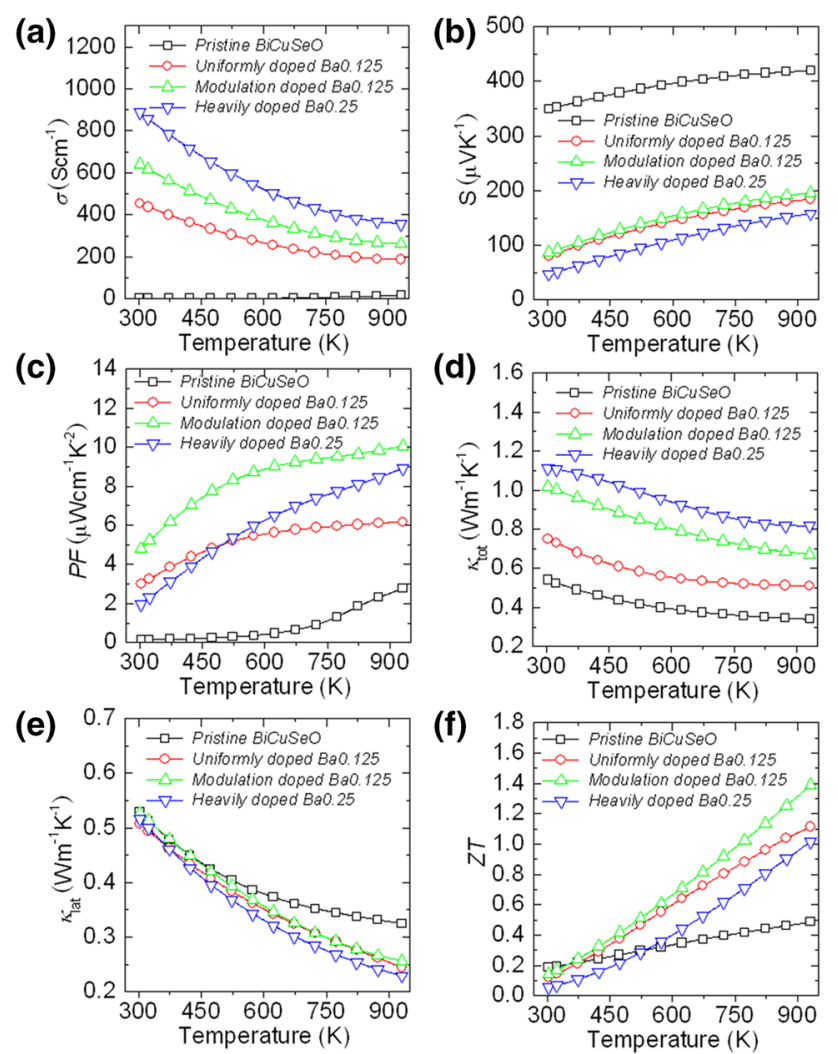

(f)

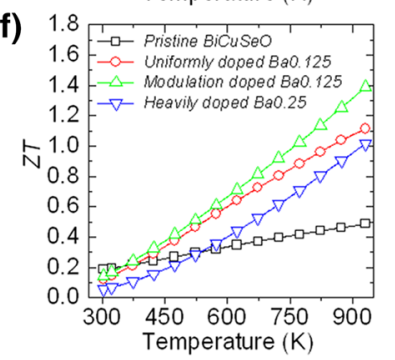

Fig. 12 The electrical conductivity (a), seebeck coefficient (b), power factor (c), thermal conductivity (d, e), and thermoelectric figure of merit (f) of modulation doped BCSO electrical conductivity, whereas Ca played the role to reduce thermal conductivity. Since $\mathrm{Pb}$ has a delocalised $6 \mathrm{~s}$ orbital that has a lone pair of electrons and due to an increased effective mass, Seebeck coefficient and electrical conductivity improve better than any other elemental doping. On the other hand, $\mathrm{Ca}$ induces both mass fluctuation (difference in mass), size, and strain field fluctuation (difference in interatomic coupling force) leading to minimum thermal conductivity. Though the solubility limit of $\mathrm{Pb}$ is $6-7 \%$, higher amount of $\mathrm{Pb}$ exhibited formation of nanoprecipitates which lead to reduction in lattice thermal conductivity. Though the pristine BCSO are known to exhibit high Seebeck coefficient, upon dual doping, it decreases to $175 \mu \mathrm{V} / \mathrm{K}$ at $873 \mathrm{~K}$ which three times is lower. Thus, the improvement in electrical conductivity coupled with a moderate Seebeck coefficient gives rise to a promising power factor of $1.0 \times 10^{-3} /$ $\mathrm{Wm} / \mathrm{K}^{2}$ for $x=0.06$ as compared to $2.2 \times 10^{-4} / \mathrm{Wm} / \mathrm{K}^{2}$ at $873 \mathrm{~K}$. The formation of Bi-rich nanoinclusions and $\mathrm{CaO}_{2}$ contributes to phonon scattering leading to a reduction in lattice thermal conductivity from $\sim 3.8$ to $\sim 2.9 \mathrm{~W} / \mathrm{mK}$ at $873 \mathrm{~K}$. All the factors combined together lead to a high $Z T$ of $\sim 1.5$ at $873 \mathrm{~K}$ [119].

$Z T$ as good as 1.09 was reported in 2016 by Das et al. for the pristine sample of $\mathrm{BaCuSeO}$. However, the high $Z T$ was attributed to a reduction in thermal conductivity $0.19 \mathrm{~W} / \mathrm{mK}$ at $773 \mathrm{~K}$ due to all length scale phonon scattering by micrometre-sized grains, point defects, naturally layered structure, and oxygen vacancies [120]. Replacing $\mathrm{Sb}$ at the Bi site and $\mathrm{Te}$ in Se site by a proportion of $8 \mathrm{~mol} \%$ $\left(\mathrm{Bi}_{0.92} \mathrm{Sb}_{0.08} \mathrm{CuSe}_{0.92} \mathrm{Te}_{0.08}\right)$ remarkably increased the $Z T$ to 1.19 at $873 \mathrm{~K}$. This increase in $Z T$ was due to the increase in band covalency and increase in carrier concentration due to $\mathrm{Sb} / \mathrm{Te}$ co-doping. Another reason was attributed to the smaller grain size due to long hours ( $16 \mathrm{~h}$ ) of ball milling and $\mathrm{Cu}$ vacancies created which lead to an increase in hole concentration eventually leading to better electrical conductivity. $\mathrm{Sb} / \mathrm{Te}$ co-doping was also responsible for the reduction in thermal conductivity as it leads to mass fluctuation and strain field fluctuation by the point defects and nanostructurization [121].

\section{Effect of texturization}

Since BCSO is a highly anisotropic material, texturizing these materials would lead to an improvement in the transport properties with respect to the direction of measurement. Hot forging is a method adopted for inducing the texturization in samples. Hot forging leads to higher order of grain alignment which was seen in BCSO with Ba doping. Preferential orientation of grains was seen to get shifted from (102) to (003) direction. It was seen that as the number of hot forging steps increases, the orientation along (003) became more prominent. While the non-textured $(0 \mathrm{~T})$ samples exhibited 
least anisotropy during the transport property measurements, the textured samples exhibited maximum anisotropy (increased with number of hot forging steps). Since the grains arrange themselves in the form of platelets along the $a$ - and $b$-axis, i.e., perpendicular to pressing direction evident from the SEM, $z$-Euler images and inverse pole figures, as shown in Fig. 13. The inverse pole figures especially highlight the high grain orientation along the $c$-axis for $3 \mathrm{~T} \perp$ sample as compared to $0 \mathrm{~T} \perp$. The grain boundary density decreases in this direction leading to increase in both electrical conductivity and thermal conductivity.

However, along the parallel cut direction, since the grain boundary density is greater, it leads to a decrease in transport properties. Electrical conductivity increases from 450 to $700 \mathrm{~S} / \mathrm{cm}$ at room temperature for three times hot forged sample that was cut perpendicular direction. While Hall effect showed not much variation in carrier concentration, so the improvement in electrical conductivity was attributed to an increase in carrier mobility $(2 / \mathrm{cm} / \mathrm{V} / \mathrm{s}$ for $0 \mathrm{~T} \perp$ and $4 / \mathrm{cm} / \mathrm{V} / \mathrm{s}$ for $3 \mathrm{~T} \perp$ ). The transport property improvement along the $\perp$ cut samples was attributed to the higher grain alignment as confirmed from the XRD. While the Seebeck coefficient was seen to be independent of any such grain orientation resulting in close to $187 \mu \mathrm{V} / \mathrm{K}$ at $923 \mathrm{~K}$ for all the samples, power factor for the $3 \mathrm{~T} \perp$ sample was the highest $\left(8 \mu \mathrm{W} / \mathrm{cm} / \mathrm{K}^{2}\right.$ AT $\left.923 \mathrm{~K}\right)$. Though thermal conductivity would increase with hot forging, the ratio of electrical to thermal conductivity was the highest for $3 \mathrm{~T} \perp$ resulting in a high $Z T$ of $\sim 1.4$ at $923 \mathrm{~K}$ [112].

\section{Other oxides}

In addition to the oxide-based systems discussed above, there are also a few other materials that are researched upon. One class of them is the double perovskites. Double perovskites are an interesting class of materials that exhibit half-metallic ground state in which conduction electrons are fully spin-polarized. The potential of such double perovskite-based materials for thermoelectric application is highlighted by Roy et al. and high Seebeck coefficient $(290 \mu \mathrm{V} / \mathrm{K}$ at $1124 \mathrm{~K}$ ) for material like $\mathrm{Sr}_{2} \mathrm{TiFeO}_{6}$ has been reported [122]. $Z T$ of 0.29 at $1223 \mathrm{~K}$ was later reported by the team for $p$-type $\mathrm{Ba}_{x} \mathrm{Sr}_{2-x} \mathrm{TiCoO}_{6}(x=0.2)$. This material exhibited glass-like behaviour. Thermal conductivity was reported to be within 0.01 to $0.55 \mathrm{~W} / \mathrm{mK}$ which is very low as compared
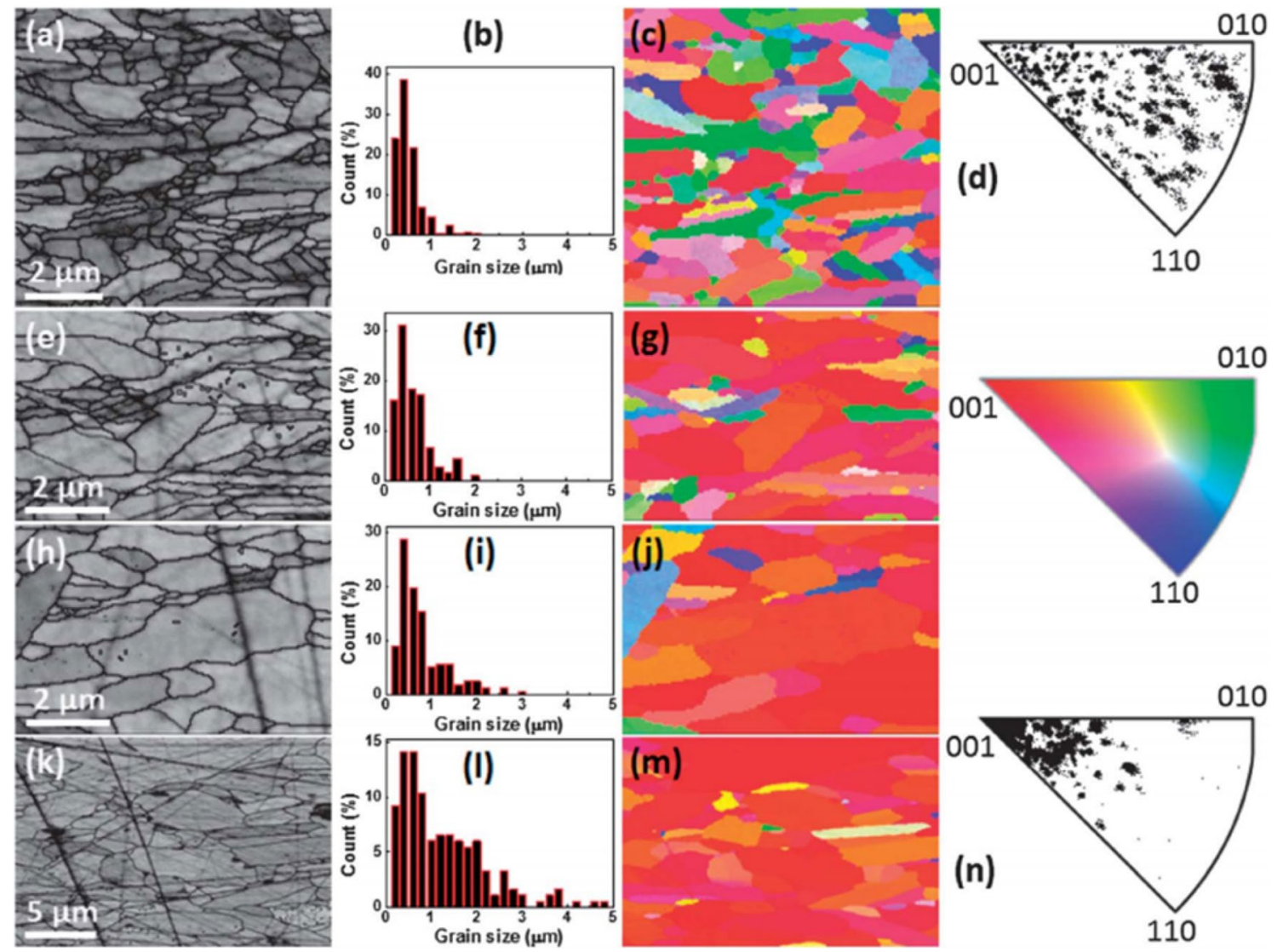

Fig. 13 The microstructure (a, e, h, k), grain size distribution $(\mathbf{b}, \mathbf{f}, \mathbf{i}, \mathbf{l}), z$-Euler images $(\mathbf{c}, \mathbf{g}, \mathbf{j}, \mathbf{m})$ of $0,1,2$, and $3 \mathrm{~T} \perp$ samples, respectively, and the inverse pole figures $(\mathbf{d}, \mathbf{n})$ for 0 and $3 \mathrm{~T} \perp$ samples 


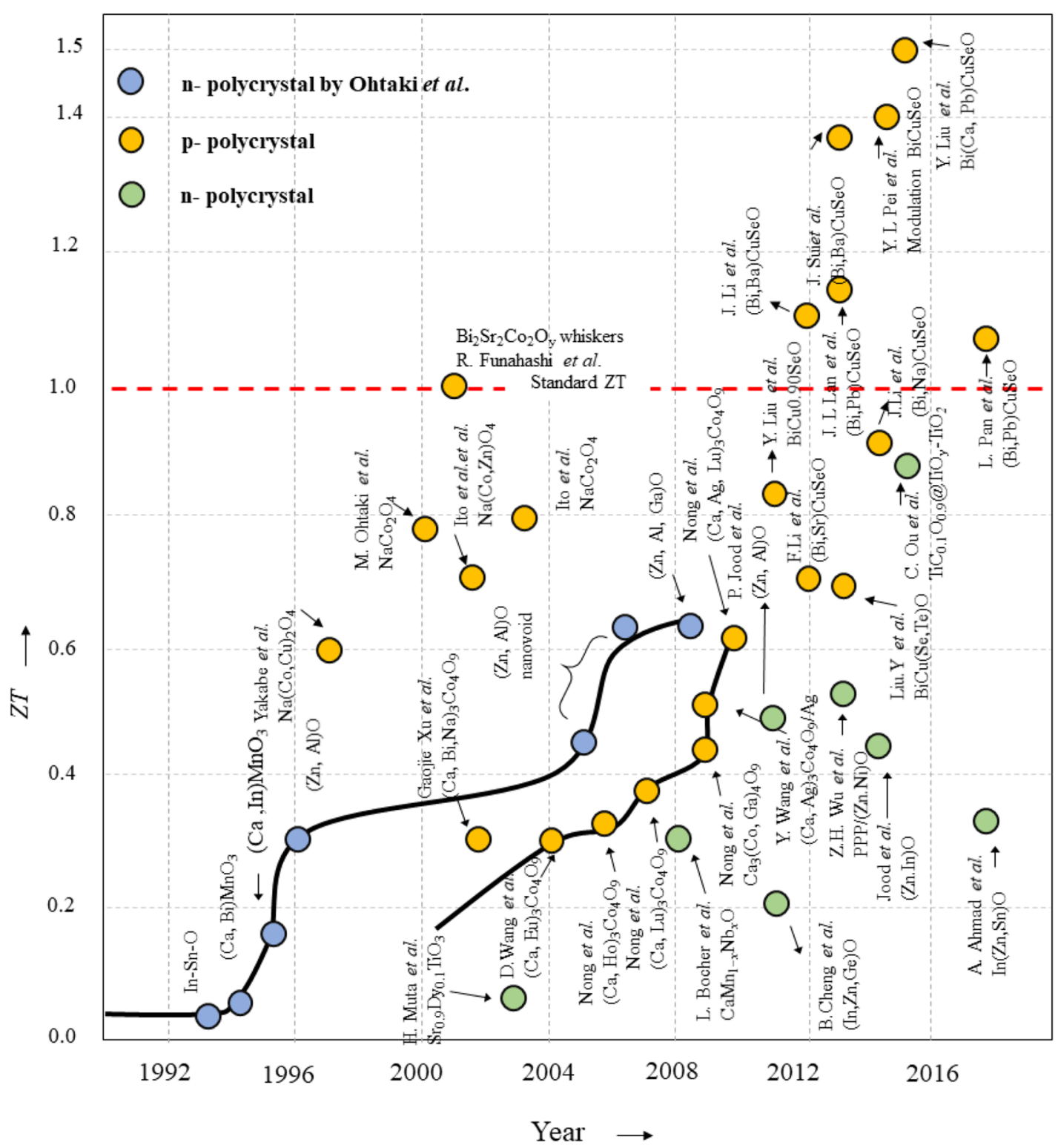

Fig. 14 Representation of the development of thermoelectric oxides over the years

to the state-of-the-art materials existing in the market. The low thermal conductivity, however, was attributed to the phonon scattering in the crystal due to multiple cations, the transition from relaxor to the glassy state after Burns temperature and shorter grain size [123]. Increasing Ba composition to $x=0.25$ showed a very high Seebeck coefficient of $\sim 800 \mu \mathrm{V} / \mathrm{K}$ at $1123 \mathrm{~K}$ at the cost of compromising electricidal conductivity. However, the author suggests that aliovalent substitution could tune the electrical conductivity of such materials [124]. The promising power factor of $\sim 35 \mu \mathrm{W} / \mathrm{mK}^{2}$ at $1100 \mathrm{~K}$ was reported for a composition of $n$-type $\mathrm{Ba}_{0.1} \mathrm{Sr}_{1.9} \mathrm{Fe}_{0.5} \mathrm{Mo}_{0.5} \mathrm{O}_{6}$. While thermal conductivity is taken care by the grain size and cationic phonon scattering centres, metallic electrical conductivity is shown due to the combination of $\mathrm{Sr}_{2} \mathrm{TiFeO}_{6}$ and $\mathrm{Sr}_{2} \mathrm{TiMoO}_{6}$. On adding $\mathrm{Ba}$ alongside increases the Seebeck coefficient at the cost of electrical conductivity leading to such high-power factor values [125]. Pseudobrookites $\left(\mathrm{Fe}_{2} \mathrm{TiO}_{5}\right)$ have been known for their high Seebeck coefficient of -100 to $-370 \mu \mathrm{V} / \mathrm{K}$ within the range of $286-1000 \mathrm{~K}$ and low thermal conductivity (1-1.5 W/mK within the temperature range of $673-1000 \mathrm{~K}$ ) [126]. Efforts have been done to improvise their electrical conductivity to obtain a promising $Z T$. Improvement in the electrical conductivity, thermal conductivity deuteration, and power factor was reported by et al. recently as a result of optimizing the percentage of Ti content in $\mathrm{Fe}_{2-x} \mathrm{Ti}_{1+x} \mathrm{O}_{5}$. An improvised $Z T$ of 0.014 at $1000 \mathrm{~K}$ was obtained at $x=0.25$ 


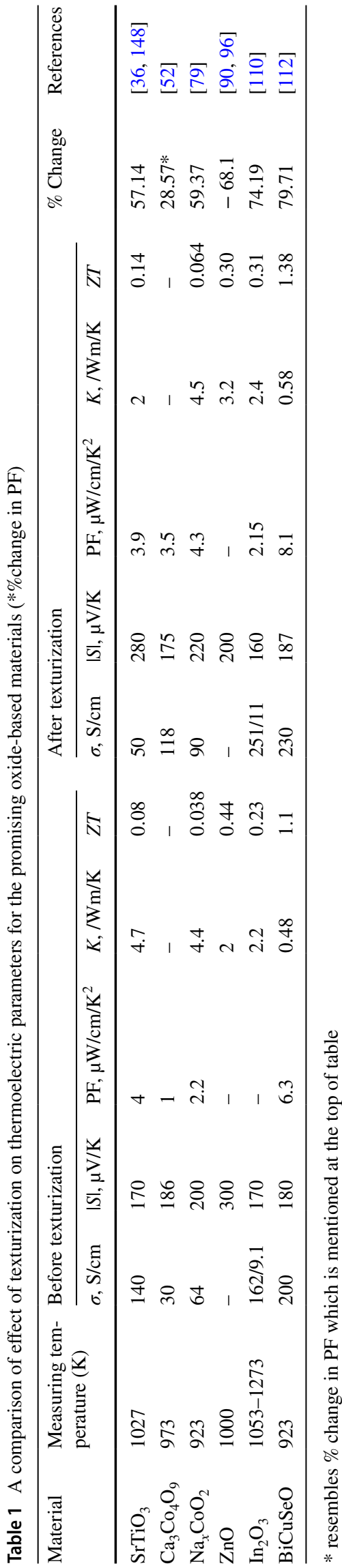

leading to a few microcracks which reduce the thermal conductivity without affecting the electrical conductivity to a great extent as in the case of $x=0.5$ [127]. Since oxides, in general, show high resistivity, oxygen deficiencies were created using vacuum sintering in a helium atmosphere to improve the electrical conductivity of Ni-doped $\mathrm{SnO}_{2}$. Power factor as good as $20.195 \mu \mathrm{V} / \mathrm{K}$ at $950 \mathrm{~K}$ was obtained for $3 \mathrm{at} \%$ doped $\mathrm{SnO}_{2}$ revealing the high-temperature performance potential of this material [128].

On a summary, the following graph depicts the different promising thermoelectric oxides reported over the years.

The development of thermoelectric $n$ and $p$-type oxides is given in Fig. 14. The various oxides labelled in Fig. 14 are-In-Sn-O [129], (Ca, Bi) $\mathrm{MnO}_{3}$ [130], (Ca,In) $\mathrm{MnO}_{3}$ [131], ( $\mathrm{Zn}, \mathrm{Al}) \mathrm{O}$ [86], ( $\mathrm{Zn}, \mathrm{Al}) \mathrm{O}$ nanovoid [88, 132], ( $\mathrm{Zn}$, $\mathrm{Al}, \mathrm{Ga}) \mathrm{O}[89],(\mathrm{Ca}, \mathrm{Eu})_{3} \mathrm{Co}_{4} \mathrm{O}_{9}$ [45], $(\mathrm{Ca}, \mathrm{Ho})_{3} \mathrm{Co}_{4} \mathrm{O}_{9}$ [133], $(\mathrm{Ca}, \mathrm{Lu})_{3} \mathrm{Co}_{4} \mathrm{O}_{9}$ [46], $\mathrm{CaMn}_{1-x} \mathrm{Nb}_{x} \mathrm{O}$ [134], $\mathrm{Ca}_{3}(\mathrm{Co}, \mathrm{Ga})_{4} \mathrm{O}_{9}$ [47], $(\mathrm{Ca}, \mathrm{Ag})_{3} \mathrm{Co}_{4} \mathrm{O}_{9} / \mathrm{Ag}$ [49], $(\mathrm{Ca}, \mathrm{Ag}, \mathrm{Lu})_{3} \mathrm{Co}_{4} \mathrm{O}_{9}$ [58], $\mathrm{Na}(\mathrm{Co}, \mathrm{Cu})_{2} \mathrm{O}_{4}$ [67], $\mathrm{Na}(\mathrm{Co}, \mathrm{Zn})_{2} \mathrm{O}_{4}$ [135], $\mathrm{NaCo}_{2} \mathrm{O}_{4}$ [136], $\mathrm{Bi}_{2} \mathrm{Sr}_{2} \mathrm{Co}_{2} \mathrm{O}_{\mathrm{y}}$ [137], ( $\left.\mathrm{Sr}, \mathrm{Dy}\right) \mathrm{TiO}_{3}$ [23], $\mathrm{Ca}(\mathrm{Mn}, \mathrm{Nb}) \mathrm{O}$ [134], (In,Zn,Ge)O [138], (Zn,Al)O [90], PPP/(Zn.Ni)O [139], (Zn. In) $\mathrm{O}$ [140], $\mathrm{TiC}_{0.1} \mathrm{O}_{0.9} @ \mathrm{TiO}_{\mathrm{y}}-\mathrm{TiO}_{2}$ [141], In(Zn,Sn)O [142], $\mathrm{BiCu} 0.90 \mathrm{SeO}$ [143], (Bi,Sr)CuSeO [117], (Bi,Ba)CuSeO [112], (Bi,Na)CuSeO [144], (Bi,Pb)CuSeO [144], (Bi,Ba) $\mathrm{CuSeO}$ [112], (Bi, $\mathrm{Pb}) \mathrm{CuSeO}$ [145], Modulation $\mathrm{BiCuSeO}$ [118], (Bi, Ba)CuSeO [146], and ( $\mathrm{Bi}, \mathrm{Ca}, \mathrm{Pb}) \mathrm{CuSeO}$ [119].

The following table highlights the overall effect of texturization on thermoelectric parameters of various materials as discussed above:

It can be seen from the table that texturization has played a vital role in improving the thermoelectric parameters. However, further studies combining methodologies such as nanostructurisation, modulation doping, and texturization could lead to further improvements. It is clear that $\mathrm{ZnO}$ based materials lack attention and improvements could be made by doping and texturing, since they can be used for high-temperature applications (Table 1).

\section{Summary}

The effect of nanostructurisation and texturization of thermoelectric ceramics and their credibility for the improvement of figure of merit is discussed. The most typical thermoelectric materials and their heat-recovery range are summarized. Thermoelectric parameters can be tuned by texturization using various methods such as reactive template grain growth method, hot press, spark plasma sintering, hotforging, etc. The representation in Fig. 15 makes it clear that more studies on $\mathrm{ZnO}, \operatorname{In}_{2} \mathrm{O}_{3} \mathrm{Ca}_{3} \mathrm{Co}_{4} \mathrm{O}_{9}$ and other oxide-based systems have to be done in the future as they 
Fig. 15 Thermoelectric materials classified based on environmental friendliness and heat-recovery range [adapted and modified from Ohtaki et al. [147]]

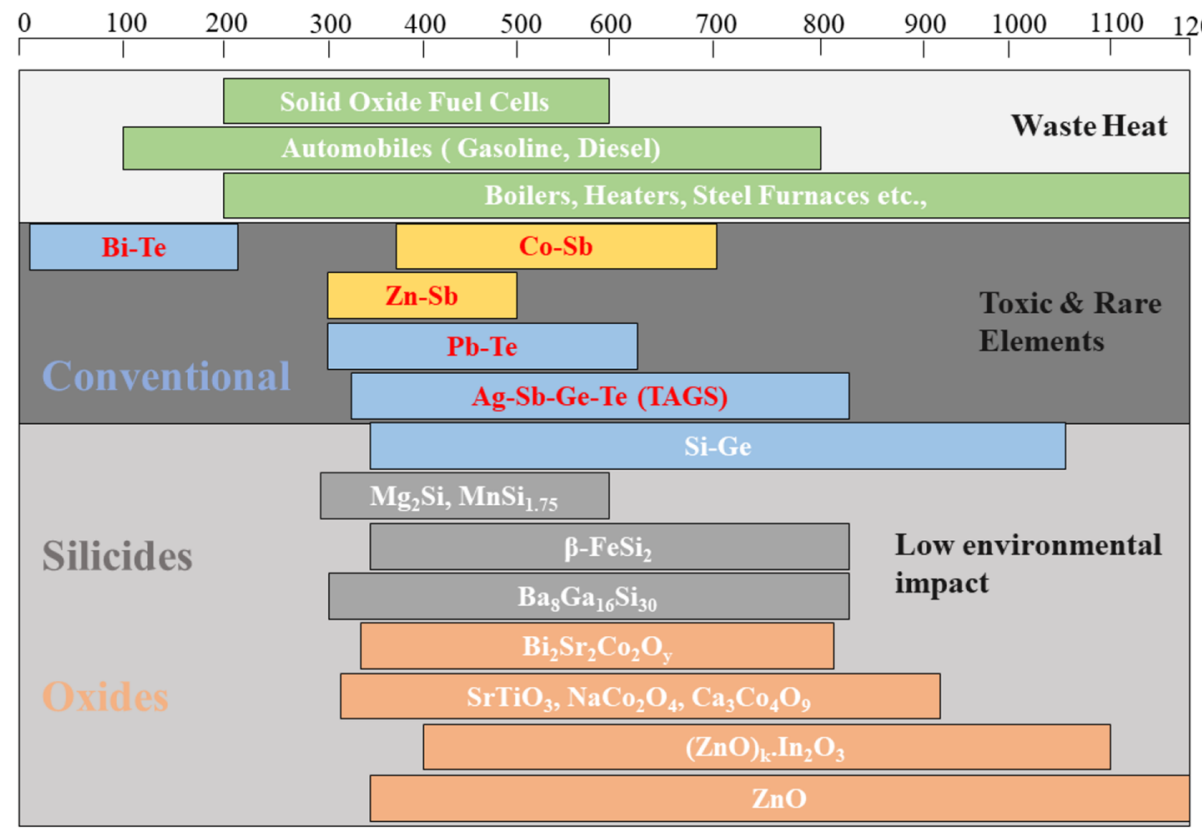

are promising for mid to high-temperature heat-recovery applications. Figure 15 is a representation of various thermoelectric materials classified based on the heat-recovery range (adapted from [147] with modification). The times ahead are expected to see a very robust alternative to the existing alloy-based thermoelectric modules based on oxide materials. A lot of work is already going on in developing the thermoelectric modules using non-metallic materials. Certainly, the progress in nanostructuring and techniques to sinter the powders without significantly affecting the nanostructure will impact the performance of newly developed thermoelectric materials.

Acknowledgements The authors would like to acknowledge the Department of Science \& Technology-Science \& Engineering Research Board (DST-SERB) for the funds received under the Grant number: SERB/F/3112/2014-15. R. Prasad would like to acknowledge Symbiosis International (Deemed University) for the award of Senior Research Fellowship.

Funding This study was funded by Department of Science \& Technology-Science \& Engineering Research Board (DST-SERB), India (Grant Number: SERB/F/3112/2014-15).

\section{Compliance with ethical standards}

Conflict of interest The authors declare that we have no conflict of interest.

Open Access This article is licensed under a Creative Commons Attribution 4.0 International License, which permits use, sharing, adaptation, distribution and reproduction in any medium or format, as long as you give appropriate credit to the original author(s) and the source, provide a link to the Creative Commons licence, and indicate if changes were made. The images or other third party material in this article are included in the article's Creative Commons licence, unless indicated otherwise in a credit line to the material. If material is not included in the article's Creative Commons licence and your intended use is not permitted by statutory regulation or exceeds the permitted use, you will need to obtain permission directly from the copyright holder. To view a copy of this licence, visit http://creativecommons.org/licenses/by/4.0/.

\section{References}

1. Zhang, D.-B., Zhang, B.-P., Ye, D.-S., Zhu, Y.-B.: Thermoelectric properties of textured $\mathrm{Zn}_{1-\mathrm{x}} \mathrm{Al}_{\mathrm{x}} \mathrm{O}$ ceramics prepared by spark plasma sintering of hydrothermally synthesized rod-shaped powders. Ceram. Int. 41(10), 14627-14634 (2015)

2. Vining, C.B.: An inconvenient truth about thermoelectrics. Nat. Mater. 8(2), 83 (2009)

3. Vedernikov, M., Iordanishvili, E.: AF Ioffe and origin of modern semiconductor thermoelectric energy conversion. In: Thermoelectrics, 1998. Proceedings ICT 98. XVII International Conference on 1998, pp. 37-42. IEEE

4. Takabatake, T., Suekuni, K., Nakayama, T., Kaneshita, E.: Phonon-glass electron-crystal thermoelectric clathrates: experiments and theory. Rev. Mod. Phys. 86(2), 669 (2014)

5. Polozine, A., Sirotinskaya, S., Schaeffer, L.: History of development of thermoelectric materials for electric power generation and criteria of their quality. Mater. Res. 17(5), 1260-1267 (2014)

6. Aswal, D.K., Basu, R., Singh, A.: Key issues in development of thermoelectric power generators: high figure-of-merit materials and their highly conducting interfaces with metallic interconnects. Energy Convers. Manag. 114, 50-67 (2016)

7. Salvador, J.R., Cho, J.Y., Ye, Z., Moczygemba, J.E., Thompson, A.J., Sharp, J.W., Koenig, J.D., Maloney, R., Thompson, T., Sakamoto, J.: Conversion efficiency of skutterudite-based thermoelectric modules. PCCP 16(24), 12510-12520 (2014)

8. Tripathi, M., Bhandari, C.: High-temperature thermoelectric performance of Si-Ge alloys. J. Phys. Condens. Matter 15(31), $5359(2003)$ 
9. Rowe, D., Bhandari, C.: Modern Thermoelectrics. Reston Publ. Co., Reston (1983). (ISBN 0-8359-4593-6)

10. Snyder, G.J., Toberer, E.S.: Complex thermoelectric materials. Nat. Mater. 7(2), 105 (2008)

11. Zhang, X., Zhao, L.-D.: Thermoelectric materials: energy conversion between heat and electricity. J. Materiomics 1(2), 92-105 (2015)

12. Weidenkaff, A.: Thermoelectricity for future sustainable energy technologies. In: European Physical Journal Web of Conferences 2017

13. Zhao, L., Wu, H., Hao, S., Wu, C.-I., Zhou, X., Biswas, K., He, J., Hogan, T.P., Uher, C., Wolverton, C.: All-scale hierarchical thermoelectrics: MgTe in PbTe facilitates valence band convergence and suppresses bipolar thermal transport for high performance. Energy Environ. Sci. 6(11), 3346-3355 (2013)

14. Gong, J., Hong, A., Shuai, J., Li, L., Yan, Z., Ren, Z., Liu, J.-M.: Investigation of the bipolar effect in the thermoelectric material $\mathrm{CaMg}_{2} \mathrm{Bi}_{2}$ using a first-principles study. PCCP $18(24)$, 16566-16574 (2016)

15. Dresselhaus, M.S., Chen, G., Tang, M.Y., Yang, R., Lee, H., Wang, D., Ren, Z., Fleurial, J.P., Gogna, P.: New directions for low-dimensional thermoelectric materials. Adv. Mater. 19(8), 1043-1053 (2007)

16. Ren, G.-K., Lan, J.-L., Ventura, K.J., Tan, X., Lin, Y.-H., Nan, C.-W.: Contribution of point defects and nano-grains to thermal transport behaviours of oxide-based thermoelectrics. Comput. Mater. 2, 16023 (2016)

17. Kinaci, A., Sevik, C., Çağın, T.: Electronic transport properties of $\mathrm{SrTiO}_{3}$ and its alloys: $\mathrm{Sr}_{1-\mathrm{x}} \mathrm{La}_{\mathrm{x}} \mathrm{TiO}_{3}$ and $\mathrm{SrTi}_{1-\mathrm{x}} \mathrm{M}_{\mathrm{x}} \mathrm{O}_{3}$ $(\mathrm{M}=\mathrm{Nb}, \mathrm{Ta})$. Phys. Rev. B 82(15), 155114 (2010)

18. Ohta, H.: Thermoelectrics based on strontium titanate. Mater. Today 10(10), 44-49 (2007)

19. Shang, P.-P., Zhang, B.-P., Liu, Y., Li, J.-F., Zhu, H.-M.: Preparation and thermoelectric properties of La-doped $\mathrm{SrTiO}_{3}$ ceramics. J. Electron. Mater. 40(5), 926-931 (2011)

20. Ohta, S., Nomura, T., Ohta, H., Koumoto, K.: High-temperature carrier transport and thermoelectric properties of heavily La-or Nb-doped $\mathrm{Sr} \mathrm{Ti} \mathrm{O}_{3}$ single crystals. J. Appl. Phys. 97(3), $034106(2005)$

21. Okuda, T., Nakanishi, K., Miyasaka, S., Tokura, Y.: Large thermoelectric response of metallic perovskites: $\mathrm{Sr}_{1-\mathrm{x}} \mathrm{La}_{\mathrm{x}} \mathrm{TiO}_{3}(0$ $\% 3 \mathrm{c} \sim \mathrm{x} \% 3 \mathrm{c} \sim 0.1$ ). Phys. Rev. B 63(11), 113104 (2001)

22. Srivastava, D., Norman, C., Azough, F., Schäfer, M.C., Guilmeau, E., Freer, R.: Improving the thermoelectric properties of $\mathrm{SrTiO}_{3}$-based ceramics with metallic inclusions. J. Alloys Compd. 731, 723-730 (2018)

23. Muta, H., Kurosaki, K., Yamanaka, S.: Thermoelectric properties of rare earth doped $\mathrm{SrTiO}_{3}$. J. Alloys Compd. 350(1-2), 292-295 (2003)

24. Kovalevsky, A., Yaremchenko, A., Populoh, S., Thiel, P., Fagg, D., Weidenkaff, A., Frade, J.: Towards a high thermoelectric performance in rare-earth substituted $\mathrm{SrTiO}_{3}$ : effects provided by strongly-reducing sintering conditions. Phys. Chem. Chem. Phys. 16(48), 26946-26954 (2014)

25. Kovalevsky, A., Populoh, S., Patrício, S., Thiel, P., Ferro, M., Fagg, D., Frade, J., Weidenkaff, A.: Design of $\mathrm{SrTiO}_{3}$-based thermoelectrics by tungsten substitution. J. Phys. Chem. C 119(9), 4466-4478 (2015)

26. Kovalevsky, A., Yaremchenko, A., Populoh, S., Weidenkaff, A., Frade, J.: Enhancement of thermoelectric performance in strontium titanate by praseodymium substitution. J. Appl. Phys. 113(5), 053704 (2013)

27. Akin, I., Li, M., Lu, Z., Sinclair, D.C.: Oxygen-loss in A-site deficient $\mathrm{Sr} 0.85 \mathrm{La} 0.10 \mathrm{TiO}_{3}$ perovskite. RSC Adv. 4(61), 32549-32554 (2014)
28. Lu, Z., Zhang, H., Lei, W., Sinclair, D.C., Reaney, I.M.: Highfigure-of-merit thermoelectric La-doped A-site-deficient $\mathrm{SrTiO}_{3}$ ceramics. Chem. Mater. 28(3), 925-935 (2016)

29. Ohta, H., Kim, S., Mune, Y., Mizoguchi, T., Nomura, K., Ohta, S., Nomura, T., Nakanishi, Y., Ikuhara, Y., Hirano, M.: Giant thermoelectric Seebeck coefficient of a two-dimensional electron gas in $\mathrm{SrTiO}_{3}$. Nat. Mater. 6(2), 129 (2007)

30. Okhay, O., Zlotnik, S., Xie, W., Orlinski, K., Gallo, M.J.H., Otero-Irurueta, G., Fernandes, A.J., Pawlak, D.A., Weidenkaff, A., Tkach, A.: Thermoelectric performance of Nb-doped $\mathrm{SrTiO}_{3}$ enhanced by reduced graphene oxide and $\mathrm{Sr}$ deficiency cooperation. Carbon 143, 215-222 (2018)

31. Tkach, A., Resende, J., Saravanan, K.V., Costa, M.E.V., DíazChao, P., Guilmeau, E., Okhay, O., Vilarinho, P.M.: Abnormal grain growth as a method to enhance the thermoelectric performance of Nb-doped strontium titanate ceramics. ACS Sustain. Chem. Eng. 6, 15988-15994 (2018)

32. Ekren, D., Azough, F., Gholinia, A., Day, S.J., HernandezMaldonado, D., Kepaptsoglou, D.M., Ramasse, Q.M., Freer, R.: Enhancing the thermoelectric power factor of $\mathrm{Sr} 0.9 \mathrm{Nd} 0.1 \mathrm{TiO}_{3}$ through control of the nanostructure and microstructure. J. Mater. Chem. A 6(48), 24928-24939 (2018)

33. Muta, H., Ieda, A., Kurosaki, K., Yamanaka, S.: Substitution effect on the thermoelectric properties of alkaline earth titanate. Mater Lett 58(30), 3868-3871 (2004)

34. Muta, H., Kurosaki, K., Yamanaka, S.: Thermoelectric properties of doped $\mathrm{BaTiO}_{3}-\mathrm{SrTiO}_{3}$ solid solution. J. Alloy Compd. 368(1-2), 22-24 (2004)

35. Yamamoto, M., Ohta, H., Koumoto, K.: Thermoelectric phase diagram in a $\mathrm{CaTiO}_{3}-\mathrm{SrTiO}_{3}-\mathrm{BaTiO}_{3}$ system. Appl. Phys. Lett. 90(7), 072101 (2007)

36. Wang, Y., Lee, K.H., Ohta, H., Koumoto, K.: Thermoelectric properties of electron doped $\mathrm{SrO}\left(\mathrm{SrTiO}_{3}\right) \mathrm{n}(\mathrm{n}=1,2)$ ceramics. J. Appl. Phys. 105(10), 103701 (2009)

37. Gao, F., Yang, S., Li, J., Qin, M., Zhang, Y., Sun, H.: Fabrication, dielectric, and thermoelectric properties of textured $\mathrm{SrTiO}_{3}$ ceramics prepared by RTGG method. Ceram. Int. 41(1), 127-135 (2015)

38. Terasaki, I., Sasago, Y., Uchinokura, K.: Large thermoelectric power in $\mathrm{NaCo}_{2} \mathrm{O}_{4}$ single crystals. Phys. Rev. B 56(20), R12685 (1997)

39. Hébert, S., Flahaut, D., Pelloquin, D., Martin, C., Maignan, A., Hejtmanek, J.: Cobalt oxides as potential thermoelectric elements: the influence of the dimensionality. In: Thermoelectrics, 2003 Twenty-Second International Conference on-ICT 2003, pp. 161-166. IEEE

40. Miyazaki, Y., Onoda, M., Oku, T., Kikuchi, M., Ishii, Y., Ono, Y., Morii, Y., Kajitani, T.: Modulated structure of the thermoelectric compound $\left[\mathrm{Ca}_{2} \mathrm{CoO}_{3}\right] 0.62 \mathrm{CoO}_{2}$. J. Phys. Soc. Jpn. 71(2), 491-497 (2002)

41. Pravarthana, D., Lebedev, O., Hebert, S., Chateigner, D., Salvador, P., Prellier, W.: High-throughput synthesis of thermoelectric $\mathrm{Ca}_{3} \mathrm{Co}_{4} \mathrm{O}_{9}$ films. Appl. Phys. Lett. 103(14), 143123 (2013)

42. Wu, T., Tyson, T.A., Chen, H., Bai, J., Wang, H., Jaye, C.: A structural change in $\mathrm{Ca}_{3} \mathrm{Co}_{4} \mathrm{O}_{9}$ associated with enhanced thermoelectric properties. J. Phys. Condens. Matter 24(45), 455602 (2012)

43. Funahashi, R., Matsubara, I., Ikuta, H., Takeuchi, T., Mizutani, U., Sodeoka, S.: An oxide single crystal with high thermoelectric performance in air. Jpn. J. Appl. Phys. 39(11B), L1127 (2000)

44. Shikano, M., Funahashi, R.: Electrical and thermal properties of single-crystalline $\left(\mathrm{Ca}_{2} \mathrm{CoO}_{3}\right)_{0.7} \mathrm{CoO}_{2}$ with a $\mathrm{Ca}_{3} \mathrm{Co}_{4} \mathrm{O}_{9}$ structure. Appl. Phys. Lett. 82(12), 1851-1853 (2003)

45. Wang, D., Chen, L., Yao, Q., Li, J.: High-temperature thermoelectric properties of $\mathrm{Ca} 3 \mathrm{Co} 4 \mathrm{O} 9+\delta$ with Eu substitution. Solid State Commun. 129(9), 615-618 (2004)

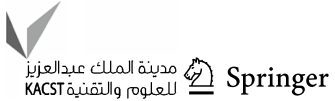


46. Nong, N., Liu, C.-J., Ohtaki, M.: High-temperature thermoelectric properties of late rare earth-doped $\mathrm{Ca} 3 \mathrm{Co} 4 \mathrm{O} 9+\delta$. J. Alloys Compd. 509(3), 977-981 (2011)

47. Nong, N., Liu, C.-J., Ohtaki, M.: Improvement on the high temperature thermoelectric performance of Ga-doped misfit-layered Ca 3 Co $4-x G a x$ O 9+ $\delta(x=0,0.05,0.1$, and 0.2). J. Alloys Compd. 491(1-2), 53-56 (2010)

48. Li, S., Funahashi, R., Matsubara, I., Ueno, K., Sodeoka, S., Yamada, H.: Synthesis and thermoelectric properties of the new oxide materials $\mathrm{Ca}_{3-\mathrm{x}} \mathrm{Bi}_{\mathrm{x}} \mathrm{Co}_{4} \mathrm{O}_{9}+\delta(0.0 \% 3 \mathrm{c} \times 3 \mathrm{c} 0.75)$. Chem. Mater. 12(8), 2424-2427 (2000)

49. Wang, Y., Sui, Y., Cheng, J., Wang, X., Su, W.: Comparison of the high temperature thermoelectric properties for Ag-doped and Ag-added $\mathrm{Ca}_{3} \mathrm{Co}_{4} \mathrm{O}_{9}$. J. Alloys Compd. 477(1-2), 817-821 (2009)

50. Saini, S., Yaddanapudi, H.S., Tian, K., Yin, Y., Magginetti, D., Tiwari, A.: Terbium ion doping in $\mathrm{Ca}_{3} \mathrm{Co}_{4} \mathrm{O}_{9}$ : a step towards high-performance thermoelectric materials. Sci. Rep. 7, 44621 (2017)

51. Prevel, M., Lemonnier, S., Klein, Y., Hébert, S., Chateigner, D., Ouladdiaf, B., Noudem, J.: Textured $\mathrm{Ca}_{3} \mathrm{Co}_{4} \mathrm{O}_{9}$ thermoelectric oxides by thermoforging process. J. Appl. Phys. 98(9), 093706 (2005)

52. Liu, Y., Lin, Y., Shi, Z., Nan, C.W., Shen, Z.: Preparation of $\mathrm{Ca}_{3} \mathrm{Co}_{4} \mathrm{O}_{9}$ and improvement of its thermoelectric properties by spark plasma sintering. J. Am. Ceram. Soc. 88(5), 1337-1340 (2005)

53. Lin, Y.-H., Lan, J., Shen, Z., Liu, Y., Nan, C.-W., Li, J.-F.: High-temperature electrical transport behaviors in textured $\mathrm{Ca}_{3} \mathrm{Co}_{4} \mathrm{O}_{9}$-based polycrystalline ceramics. Appl. Phys. Lett. 94(7), 072107 (2009)

54. Prevel, M., Reddy, E.S., Perez, O., Kobayashi, W., Terasaki, I., Goupil, C., Noudem, J.G.: Thermoelectric properties of sintered and textured Nd-substituted $\mathrm{Ca}_{3} \mathrm{Co}_{4} \mathrm{O}_{9}$ ceramics. Jpn. J. Appl. Phys. 46(10R), 6533 (2007)

55. Kenfaui, D., Chateigner, D., Gomina, M., Noudem, J.G.: Texture, mechanical and thermoelectric properties of $\mathrm{Ca}_{3} \mathrm{Co}_{4} \mathrm{O}_{9}$ ceramics. J. Alloys Compd. 490(1-2), 472-479 (2010)

56. Kenfaui, D., Lenoir, B., Chateigner, D., Ouladdiaf, B., Gomina, M., Noudem, J.G.: Development of multilayer textured $\mathrm{Ca}_{3} \mathrm{Co}_{4} \mathrm{O}_{9}$ materials for thermoelectric generators: influence of the anisotropy on the transport properties. J. Eur. Ceram. Soc. 32(10), 2405-2414 (2012)

57. Kenfaui, D., Chateigner, D., Gomina, M., Noudem, J.G.: Anisotropy of the mechanical and thermoelectric properties of hotpressed single-layer and multilayer thick $\mathrm{Ca}_{3} \mathrm{Co}_{4} \mathrm{O}_{9}$ ceramics. Int. J. Appl. Ceram. Technol. 8(1), 214-226 (2011)

58. Van, N.N., Pryds, N.: Nanostructured oxide materials and modules for high-temperature power generation from waste heat. Adv. Nat. Sci. Nanosci. Nanotechnol. 4(2), 023002 (2013)

59. Noudem, J.G., Kenfaui, D., Chateigner, D., Gomina, M.: Toward the enhancement of thermoelectric properties of lamellar $\mathrm{Ca}_{3} \mathrm{Co}_{4} \mathrm{O}_{9}$ by edge-free spark plasma texturing. Scr. Mater. 66(5), 258-260 (2012)

60. Miyazawa, K., Amaral, F., Kovalevsky, A., Graça, M.: Hybrid microwave processing of $\mathrm{Ca}_{3} \mathrm{Co}_{4} \mathrm{O}_{9}$ thermoelectrics. Ceram. Int. 42(8), 9482-9487 (2016)

61. Torres, M., Costa, F., Flahaut, D., Touati, K., Rasekh, S., Ferreira, N., Allouche, J., Depriester, M., Madre, M., Kovalevsky, A.: Significant enhancement of the thermoelectric performance in $\mathrm{Ca}_{3} \mathrm{Co}_{4} \mathrm{O}_{9}$ thermoelectric materials through combined strontium substitution and hot-pressing process. J. Eur. Ceram. Soc. 39(4), 1186-1192 (2019)

62. Bittner, M., Kanas, N., Hinterding, R., Steinbach, F., Groeneveld, D., Wemhoff, P., Wiik, K., Einarsrud, M.-A., Feldhoff, A.: Triple-phase ceramic 2D nanocomposite with enhanced thermoelectric properties. J. Eur. Ceram. Soc. 39(4), 1237 1244 (2019)

63. Takahata, K., Iguchi, Y., Tanaka, D., Itoh, T., Terasaki, I.: Low thermal conductivity of the layered oxide $(\mathrm{Na}, \mathrm{Ca}) \mathrm{Co}_{2} \mathrm{O}_{4}$ : another example of a phonon glass and an electron crystal. Phys. Rev. B 61(19), 12551 (2000)

64. Roger, M., Morris, D., Tennant, D., Gutmann, M., Goff, J., Hoffmann, J.-U., Feyerherm, R., Dudzik, E., Prabhakaran, D., Boothroyd, A.: Patterning of sodium ions and the control of electrons in sodium cobaltate. Nature 445(7128), 631 (2007)

65. Li, Q.: On the thermoelectric properties of layered cobaltates. MRS Online Proc. Libr. Arch. 886 (2005)

66. Thermoelectrics, O.: Research Signpost/ed. by K. Koumoto, I. Terasaki, N. Murayama. Trivandrum, India (2002).

67. Yakabe, H., Kikuchi, K., Terasaki, I., Sasago, Y., Uchinokura, K.: Thermoelectric properties of transition-metal oxide $\mathrm{NaCo} /$ sub 2/O/sub 4/system. In: Thermoelectrics, 1997. Proceedings ICT'97. XVI International Conference on 1997, pp. 523-527. IEEE

68. Motohashi, T., Naujalis, E., Ueda, R., Isawa, K., Karppinen, M., Yamauchi, H.: Simultaneously enhanced thermoelectric power and reduced resistivity of $\mathrm{Na}_{\mathrm{x}} \mathrm{Co}_{2} \mathrm{O}_{4}$ by controlling $\mathrm{Na}$ nonstoichiometry. Appl. Phys. Lett. 79(10), 1480-1482 (2001)

69. Seetawan, T., Amornkitbamrung, V., Burinprakhon, T., Maensiri, S., Kurosaki, K., Muta, H., Uno, M., Yamanaka, S.: Thermoelectric power and electrical resistivity of Ag-doped $\mathrm{Na}_{1.5} \mathrm{Co}_{2} \mathrm{O}_{4}$. J. Alloys Compd. 407(1-2), 314-317 (2006)

70. Kurosaki, K., Muta, H., Uno, M., Yamanaka, S.: Thermoelectric properties of $\mathrm{NaCO}_{2} \mathrm{O}_{4}$. J. Alloys Compd. 315(1-2), 234-236 (2001)

71. Seetawan, T., Amornkitbamrung, V., Burinprakhon, T., Maensiri, S., Kurosaki, K., Muta, H., Uno, M., Yamanaka, S.: Thermoelectric properties of $\mathrm{Na}_{\mathrm{x}} \mathrm{Co}_{2} \mathrm{O}_{4} / \mathrm{Ag}$ composites. J. Alloys Compd. 414(1-2), 293-297 (2006)

72. Park, K., Jang, K.: Improvement in high-temperature thermoelectric properties of $\mathrm{NaCo}_{2} \mathrm{O}_{4}$ through partial substitution of $\mathrm{Ni}$ for Co. Mater. Lett. 60(8), 1106-1110 (2006)

73. Yao, Q., Wang, D., Chen, L., Shi, X., Zhou, M.: Effects of partial substitution of transition metals for cobalt on the hightemperature thermoelectric properties of $\mathrm{Ca}_{3} \mathrm{Co}_{4} \mathrm{O}_{9+\delta}$. J. Appl. Phys. 97(10), 103905 (2005)

74. Terasaki, I., Tsukada, I., Iguchi, Y.: Impurity-induced transition and impurity-enhanced thermopower in the thermoelectric oxide $\mathrm{NaCo}_{2-\mathrm{x}} \mathrm{Cu}_{\mathrm{x}} \mathrm{O}_{4}$. Phys. Rev. B 65(19), 195106 (2002)

75. Tsai, P.-H., Zhang, T., Donelson, R., Tan, T.T., Li, S.: Power factor enhancement in $\mathrm{Zn}$-doped $\mathrm{Na}_{0.8} \mathrm{CoO}_{2}$. J. Alloys Compd. 509(16), 5183-5186 (2011)

76. Krasutskaya, N., Klyndyuk, A., Evseeva, L., Tanaeva, S.: Synthesis and properties of $\mathrm{Na}_{\mathrm{x}} \mathrm{CoO}_{2}(\mathrm{x}=0.55,0.89)$ oxide thermoelectrics. Inorg. Mater. 52(4), 393-399 (2016)

77. Richter, R., Shopova, D., Xie, W., Weidenkaff, A., Lechermann, F.: Thermopower enhancement from engineering the $\mathrm{Na}_{0.7} \mathrm{CoO}_{2}$ interacting fermiology via $\mathrm{Fe}$ doping. Adv. Condens. Matter Phys. 2018, 1-7 (2018)

78. Behera, S., Kamble, V.B., Vitta, S., Umarji, A.M., Shivakumara, C.: Synthesis, structure and thermoelectric properties of $\mathrm{La}_{1-\mathrm{x}} \mathrm{Na}_{\mathrm{x}} \mathrm{CoO}_{3}$ perovskite oxides. Bull. Mater. Sci. 40(7), 1291-1299 (2017)

79. Zhang, W., Liu, P., Wang, Y., Zhu, K., Tai, G., Liu, J., Wang, J., Yan, K., Zhang, J.: Textured $\mathrm{Na}_{\mathrm{x}} \mathrm{CoO}_{2}$ ceramics sintered from hydrothermal platelet nanocrystals: growth mechanism and transport properties. J. Electron. Mater. 47(7), 4070-4077 (2018)

80. Look, D.C.: Progress in $\mathrm{ZnO}$ materials and devices. J. Electron. Mater. 35(6), 1299-1305 (2006) 
81. Huang, M.H., Mao, S., Feick, H., Yan, H., Wu, Y., Kind, H., Weber, E., Russo, R., Yang, P.: Room-temperature ultraviolet nanowire nanolasers. Science 292(5523), 1897-1899 (2001)

82. Pearton, S., Norton, D., Ip, K., Heo, Y., Steiner, T.: Recent progress in processing and properties of $\mathrm{ZnO}$. Prog. Mater Sci. 50(3), 293-340 (2005)

83. Serier, H., Gaudon, M., Ménétrier, M.: Al-doped $\mathrm{ZnO}$ powdered materials: Al solubility limit and IR absorption properties. Solid State Sci. 11(7), 1192-1197 (2009)

84. Hasnidawani, J., Azlina, H., Norita, H., Bonnia, N., Ratim, S., Ali, E.: Synthesis of $\mathrm{ZnO}$ nanostructures using sol-gel method. Proc. Chem. 19, 211-216 (2016)

85. Ogi, T., Hidayat, D., Iskandar, F., Purwanto, A., Okuyama, K.: Direct synthesis of highly crystalline transparent conducting oxide nanoparticles by low pressure spray pyrolysis. Adv. Powder Technol. 20(2), 203-209 (2009)

86. Ohtaki, M., Tsubota, T., Eguchi, K., Arai, H.: High-temperature thermoelectric properties of $\left(\mathrm{Zn}_{1-\mathrm{x}} \mathrm{Al}_{\mathrm{x}}\right) \mathrm{O}$. J. Appl. Phys. 79(3), 1816-1818 (1996)

87. Ohtaki, M., Araki, K.: Thermoelectric properties and thermopower enhancement of Al-doped $\mathrm{ZnO}$ with nanosized pore structure. J. Ceram. Soc. Jpn. 119(1395), 813-816 (2011)

88. Ohtaki, M., Hayashi, R.: Enhanced thermoelectric performance of nanostructured $\mathrm{ZnO}$ : a possibility of selective phonon scattering and carrier energy filtering by nanovoid structure. In: Thermoelectrics, 2006. ICT'06. 25th International Conference on 2006, pp. 276-279. IEEE

89. Ohtaki, M., Araki, K., Yamamoto, K.: High thermoelectric performance of dually doped $\mathrm{ZnO}$ ceramics. J. Electron. Mater. 38(7), 1234-1238 (2009)

90. Jood, P., Mehta, R.J., Zhang, Y., Peleckis, G., Wang, X., Siegel, R.W., Borca-Tasciuc, T., Dou, S.X., Ramanath, G.: Al-doped zinc oxide nanocomposites with enhanced thermoelectric properties. Nano Lett. 11(10), 4337-4342 (2011)

91. Zakharchuk, K., Widenmeyer, M., Alikin, D.O., Xie, W., Populoh, S., Mikhalev, S.M., Tselev, A., Frade, J., Weidenkaff, A., Kovalevsky, A.: Self-forming nanocomposite concept for $\mathrm{ZnO}$ based thermoelectrics. J. Mater. Chem. A 6, 13386-13396 (2018)

92. Zha, X., Gao, L., Bai, H., Fu, N., Wang, J., Fu, G., Wang, S.: Towards a high thermoelectric performance in $\mathrm{CdO}$ ceramics by introducing multiscale scattering centers via $\mathrm{ZnCO} 3$ doping. Mater. Res. Express 5(3), 035908 (2018)

93. Prasad, R., Bhame, S.D., Walke, P.: Structural and optical studies on nanosized thermoelectric oxide- $\mathrm{Zn}_{1-\mathrm{x}} \mathrm{Al}_{\mathrm{x}} \mathrm{O}$. Int. J. Nanosci. 17(5), 1850038 (2018)

94. Zakharchuk, K.V., Tobaldi, D.M., Xiao, X., Xie, W., Mikhalev, S.M., Martins, J.F., Frade, J.R., Weidenkaff, A., Kovalevsky, A.V.: Synergistic effects of zirconium-and aluminum co-doping on the thermoelectric performance of zinc oxide. J. Eur. Ceram. Soc. 39, 1222-1229 (2018)

95. Paulson, A., Sabeer, N.M., Pradyumnan, P.: A synergetic approach of band gap engineering and reduced lattice thermal conductivity for the enhanced thermoelectric property in Dy ion doped ZnO. J. Alloy Compd. 786, 581-587 (2019)

96. Han, L., Van Nong, N., Zhang, W., Hung, L.T., Holgate, T., Tashiro, K., Ohtaki, M., Pryds, N., Linderoth, S.: Effects of morphology on the thermoelectric properties of Al-doped ZnO. RSC Adv. 4(24), 12353-12361 (2014)

97. Jia, J., Ow-Yang, C., Inan Akmehmet, G., Nakamura, S.-I., Kato, K., Shigesato, Y.: Formation of homologous In2O3 (ZnO) m thin films and its thermoelectric properties. J. Vac. Sci. Technol. A Vac. Surf. Films 34(4), 041507 (2016)

98. Tani, T., Isobe, S., Seo, W.-S., Koumoto, K.: Thermoelectric properties of highly textured $(\mathrm{ZnO}) 5 \operatorname{In}_{2} \mathrm{O}_{3}$ ceramics. J. Mater. Chem. 11(9), 2324-2328 (2001)
99. Peng, H., Song, J.-H., Hopper, E.M., Zhu, Q., Mason, T.O., Freeman, A.J.: Possible n-type carrier sources in $\mathrm{In} 2 \mathrm{O} 3(\mathrm{ZnO}) \mathrm{k}$. Chem. Mater. 24(1), 106-114 (2011)

100. Wen, J., Wu, L., Zhang, X.: A unique arrangement of atoms for the homologous compounds $\mathrm{InMO}_{3}(\mathrm{ZnO}) \mathrm{m}(\mathrm{M}=\mathrm{Al}, \mathrm{Fe}, \mathrm{Ga}$, and In). J. Appl. Phys. 111(11), 113716 (2012)

101. Košir, M., Podlogar, M., Daneu, N., Rečnik, A., Guilmeau, E., Bernik, S.: Phase formation, microstructure development and thermoelectric properties of $(\mathrm{ZnO}) \mathrm{k} \mathrm{In}_{2} \mathrm{O}_{3}$ ceramics. J. Eur. Ceram. Soc. 37(8), 2833-2842 (2017)

102. Bernik, S., Košir, M., Guilmeau, E.: Microstructure and thermoelectric characteristics of $(\mathrm{ZnO}) \mathrm{k} \times \operatorname{In}_{2} \mathrm{O}_{3}$ : based ceramics $(\mathrm{k}=5$ and 11). Zaštita materijala 57(2), 318-325 (2016)

103. Košir, M., Podlogar, M., Daneu, N., Rečnik, A., Guilmeau, E., Bernik, S.: Phase formation, microstructure development and thermoelectric properties of $(\mathrm{ZnO}) \mathrm{kIn}_{2} \mathrm{O}_{3}$ ceramics. J. Eur. Ceram. Soc. 37(8), 2833-2842 (2017)

104. Košir, M., Čeh, M., Ow-Yang, C.W., Guilmeau, E., Bernik, S.: Structural features and thermoelectric properties of Al-doped ( $\mathrm{ZnO}) 5 \mathrm{In}_{2} \mathrm{O}_{3}$ homologous phases. J. Am. Ceram. Soc. 100(8), 3712-3721 (2017)

105. Bérardan, D., Guilmeau, E., Maignan, A., Raveau, B.: $\operatorname{In}_{2} \mathrm{O}_{3}$ : Ge, a promising n-type thermoelectric oxide composite. Solid State Commun. 146(1-2), 97-101 (2008)

106. Bhame, S., Zhou, T., Guilmeau, E., Kinemuchi, Y., Delorme, F., Raveau, B.: Synthesis and thermoelectric properties of oxygen deficient fluorite derivative $\mathrm{Ga}_{3-\mathrm{x}} \mathrm{In}_{5+\mathrm{x}} \mathrm{Sn}_{2} \mathrm{O}_{16}$. J. Appl. Phys. 108(9), 093708 (2010)

107. Zhou, T., Bhame, S., Guilmeau, E., Marinel, S., Raveau, B.: Enhanced densification and thermoelectric performance of $\mathrm{In}_{4} \mathrm{Sn}_{3} \mathrm{O}_{12}$ by reactive sintering in the In-Sn-Ga-O System. J. Am. Ceram. Soc. 94(11), 3733-3737 (2011)

108. Combe, E., Bhame, S.D., Guilmeau, E., Boschini, F., Cloots, R.: Synthesis of $\mathrm{In}_{2-\mathrm{x}} \mathrm{Ge}_{\mathrm{x}} \mathrm{O}_{3}$ nanopowders for thermoelectric applications. J. Mater. Res. 27(2), 500-505 (2012)

109. Isobe, S., Tani, T., Masuda, Y., Seo, W.-S., Koumoto, K.: Thermoelectric performance of yttrium-substituted $(\mathrm{ZnO}) 5 \operatorname{In}_{2} \mathrm{O}_{3}$ improved through ceramic texturing. Jpn. J. Appl. Phys. 41(2R), 731 (2002)

110. Kaga, H., Asahi, R., Tani, T.: Thermoelectric properties of highly textured Ca-doped $(\mathrm{ZnO}) \mathrm{mIn}_{2} \mathrm{O}_{3}$ ceramics. Jpn. J. Appl. Phys. 43(10R), 7133 (2004)

111. Luu, S.D., Vaqueiro, P.: Layered oxychalcogenides: Structural chemistry and thermoelectric properties. J. Materiomics 2(2), 131-140 (2016)

112. Sui, J., Li, J., He, J., Pei, Y.-L., Berardan, D., Wu, H., Dragoe, N., Cai, W., Zhao, L.-D.: Texturation boosts the thermoelectric performance of BiCuSeO oxyselenides. Energy Environ. Sci. 6(10), 2916-2920 (2013)

113. Lee, C., An, T.-H., Gordon, E.E., Ji, H.S., Park, C., Shim, J.-H., Lim, Y.S., Whangbo, M.-H.: Seebeck coefficients of layered $\mathrm{BiCuSeO}$ phases: analysis of their hole-density dependence and quantum confinement effect. Chem. Mater. 29(5), 2348-2354 (2017)

114. Zhao, L.-D., He, J., Berardan, D., Lin, Y., Li, J.-F., Nan, C.-W., Dragoe, N.: BiCuSeO oxyselenides: new promising thermoelectric materials. Energy Environ. Sci. 7(9), 2900-2924 (2014)

115. Zhao, L., Berardan, D., Pei, Y., Byl, C., Pinsard-Gaudart, L., Dragoe, $\mathrm{N} .: \mathrm{Bi}_{1-\mathrm{x}} \mathrm{Sr}_{\mathrm{x}} \mathrm{CuSeO}$ oxyselenides as promising thermoelectric materials. Appl. Phys. Lett. 97(9), 092118 (2010)

116. Pei, Y.-L., He, J., Li, J.-F., Li, F., Liu, Q., Pan, W., Barreteau, C., Berardan, D., Dragoe, N., Zhao, L.-D.: High thermoelectric performance of oxyselenides: intrinsically low thermal conductivity of Ca-doped BiCuSeO. NPG Asia Mater. 5(5), e47 (2013)

117. Li, F., Li, J.-F., Zhao, L.-D., Xiang, K., Liu, Y., Zhang, B.-P., Lin, Y.-H., Nan, C.-W., Zhu, H.-M.: Polycrystalline BiCuSeO oxide 
as a potential thermoelectric material. Energy Environ. Sci. 5(5), 7188-7195 (2012)

118. Pei, Y.-L., Wu, H., Wu, D., Zheng, F., He, J.: High thermoelectric performance realized in a $\mathrm{BiCuSeO}$ system by improving carrier mobility through 3D modulation doping. J. Am. Chem. Soc. 136(39), 13902-13908 (2014)

119. Liu, Y., Zhao, L.D., Zhu, Y., Liu, Y., Li, F., Yu, M., Liu, D.B., Xu, W., Lin, Y.H., Nan, C.W.: Synergistically optimizing electrical and thermal transport properties of $\mathrm{BiCuSeO}$ via a dualdoping approach. Adv. Energy Mater. 6(9), 1502423 (2016)

120. Das, S., Chetty, R., Wojciechowski, K., Suwas, S., Mallik, R.C.: Thermoelectric properties of Sn doped BiCuSeO. Appl. Surf. Sci. 418, 238-245 (2017)

121. Feng, B., Li, G., Pan, Z., Hu, X., Liu, P., Li, Y., He, Z., Fan, $X . A .:$ Enhancing thermoelectric and mechanical performances in $\mathrm{BiCuSeO}$ by increasing bond covalency and nanostructuring. J. Solid State Chem. 265, 306-313 (2018)

122. Roy, P., Bose, I., Maiti, T.: Synthesis and characterization of $\mathrm{Sr}_{2} \mathrm{TiMO}_{6}(\mathrm{M}=\mathrm{Fe}, \mathrm{Co})$ double perovskites for high temperature thermoelectric applications. Integr. Ferroelectr. 174(1), 34-42 (2016)

123. Saxena, M., Roy, P., Acharya, M., Bose, I., Tanwar, K., Maiti, T.: Enhanced thermoelectric figure-of-merit in environmentally benign $\mathrm{Ba}_{\mathrm{x}} \mathrm{Sr}_{2-\mathrm{x}} \mathrm{TiCoO}_{6}$ double perovskites. Appl. Phys. Lett. 109(26), 263903 (2016)

124. Roy, P., Waghmare, V., Maiti, T.: Environmentally friendly $\mathrm{Ba}_{\mathrm{x}}$ $\mathrm{Sr}_{2-\mathrm{x}} \mathrm{TiFeO}_{6}$ double perovskite with enhanced thermopower for high temperature thermoelectric power generation. RSC Adv. 6(60), 54636-54643 (2016)

125. Saxena, M., Maiti, T.: Evaluation of $\mathrm{Ba}$ doped $\mathrm{Sr}_{2} \mathrm{TiFe}_{0.5} \mathrm{Mo}_{0.5}$ $\mathrm{O}_{6}$ double perovskites for high temperature thermoelectric power generation. Scr. Mater. 155, 85-88 (2018)

126. Chen, C., Giovannelli, F., Duclère, J.-R., Delorme, F.: Thermoelectric properties of $\mathrm{Fe}_{2}\left(\mathrm{Ti}_{1-\mathrm{x}} \mathrm{Nb}_{\mathrm{x}}\right) \mathrm{O}_{5}$ pseudobrookite ceramics with low thermal conductivity. J. Eur. Ceram. Soc. 37(15), 4681-4685 (2017)

127. Chen, C., Giovannelli, F., Delorme, F.: Thermoelectric properties of $\mathrm{Fe}_{2-\mathrm{x}} \mathrm{Ti}_{1+\mathrm{x}} \mathrm{O}_{5}$ solid solutions: Influence of microcracking and Nb substitution. Ceram. Int. 44(17), 21794-21799 (2018)

128. Paulson, A., Sabeer, N.M., Pradyumnan, P.: Enhanced thermoelectric property of oxygen deficient nickel doped $\mathrm{SnO}_{2}$ for high temperature application. Mater. Res. Express 5(4), 045511 (2018)

129. Ohtaki, M.: Thermoelectric properties and applicability of In_2O_3-based mixed metal oxides for thermoelectric conversion at high temperature. In: Proceedings of The 12th International Conference on Thermoelecrics, K. Matsuura ed., Yokohama, XII, ICT 1993, pp. 212-217

130. Ohtaki, M., Koga, H., Eguchi, K., Arai, H.: Thermoelectric properties of $\left(\mathrm{Ca}_{1-\mathrm{x}} \mathrm{Bi}_{\mathrm{x}}\right) \mathrm{MnO}_{3}$ perovskite-type oxides as a new material for high temperature thermoelectric conversion. In: AIP Conference Proceedings 1994, vol. CONF-940830

131. Ohtaki, M., Koga, H., Tokunaga, T., Eguchi, K., Arai, H.: Electrical transport properties and high-temperature thermoelectric performance of $\left(\mathrm{Ca}_{0.9} \mathrm{M}_{0.1}\right) \mathrm{MnO}_{3}(\mathrm{M}=\mathrm{Y}, \mathrm{La}, \mathrm{Ce}, \mathrm{Sm}, \mathrm{In}, \mathrm{Sn}, \mathrm{Sb}$, $\mathrm{Pb}, \mathrm{Bi})$. J. Solid State Chem. 120(1), 105-111 (1995).

132. Hayashi, R., Ohtaki, M.: Selective phonon scattering and thermoelectric properties of $\mathrm{ZnO}$-based oxide with nanovoid structure. In: Preprints of Annual Meeting of The Ceramic Society of Japan Preprints of Fall Meeting of The Ceramic Society of Japan Annual Meeting of The Ceramic Society of Japan, 2005, pp. 256-256. The Ceramic Society of Japan (2005)

133. Nong, N., Ohtaki, M.: Thermoelectric properties and local electronic structure of rare earth-doped $\mathrm{Ca}_{3} \mathrm{Co}_{2} \mathrm{O}_{6}$. In:
Thermoelectrics, 2006. ICT'06. 25th International Conference on 2006, pp. 62-65. IEEE

134. Bocher, L., et al.: CaMn1- x Nb x O3 (x $\leq 0.08)$ perovskite-type phases as promising new high-temperature n-type thermoelectric materials. Inorg. Chem. 47(18), 8077-8085 (2008)

135. Ito, M., Nagira, T., Oda, Y., Katsuyama, S., Majima, K., Nagai, H.: Effect of partial substitution of $3 \mathrm{~d}$ transition metals for Co on the thermoelectric properties of $\mathrm{Na}_{\mathrm{x}} \mathrm{Co}_{2} \mathrm{O}_{4}$. Mater. Trans. 43(3), 601-604 (2002)

136. Ohtaki, M., Maeda, E.: Microstructures and thermoelectric properties of $\mathrm{NaCo}_{2} \mathrm{O}_{4}$ prepared by double-step sintering. J. Jpn. Soc. Powder Powder Metall. 47(11), 1159-1164 (2000)

137. Funahashi, R., Shikano, $\mathrm{M} .: \mathrm{Bi}_{2} \mathrm{Sr}_{2} \mathrm{Co}_{2} \mathrm{O}_{\mathrm{y}}$ whiskers with high thermoelectric figure of merit. Appl. Phys. Lett. 81(8), 1459$1461(2002)$

138. Cheng, B., Fang, H., Lan, J., Liu, Y., Lin, Y.H., Nan, C.W.: Thermoelectric performance of $\mathrm{Zn}$ and Ge Co-doped $\mathrm{In}_{2} \mathrm{O}_{3}$ finegrained ceramics by the spark plasma sintering. J. Am. Ceram. Soc. 94(8), 2279-2281 (2011)

139. Wu, Z.-H., Xie, H.-Q., Zhai, Y.-B.: Enhanced thermoelectric figure of merit in nanostructured $\mathrm{ZnO}$ by nanojunction effect. Appl. Phys. Lett. 103(24), 243901 (2013)

140. Jood, P., Mehta, R.J., Zhang, Y., Borca-Tasciuc, T., Dou, S.X., Singh, D.J., Ramanath, G.: Heavy element doping for enhancing thermoelectric properties of nanostructured zinc oxide. RSC Adv. 4(13), 6363-6368 (2014)

141. Ou, C., Hou, J., Wei, T.-R., Jiang, B., Jiao, S., Li, J.-F., Zhu, H.: High thermoelectric performance of all-oxide heterostructures with carrier double-barrier filtering effect. NPG Asia Mater. 7(5), e182 (2015)

142. Ahmad, A., Umer, M., Tan, X., Liu, R., Mohmad, F., Hussain, M., Ren, G.-K., Lin, Y.-H.: High-temperature electrical and thermal transport behaviors of $\operatorname{In}_{2} \mathrm{O}_{3}$-based ceramics by $\mathrm{Zn}-\mathrm{Sn}$ co-substitution. J. Appl. Phys. 123(24), 245108 (2018)

143. Liu, Y., Zhao, L.-D., Liu, Y., Lan, J., Xu, W., Li, F., Zhang, B.-P., Berardan, D., Dragoe, N., Lin, Y.-H.: Remarkable enhancement in thermoelectric performance of $\mathrm{BiCuSeO}$ by $\mathrm{Cu}$ deficiencies. J. Am. Chem. Soc. 133(50), 20112-20115 (2011)

144. Li, J., Sui, J., Pei, Y., Meng, X., Berardan, D., Dragoe, N., Cai, W., Zhao, L.-D.: The roles of Na doping in $\mathrm{BiCuSeO}$ oxyselenides as a thermoelectric material. J. Mater. Chem. A 2(14), 4903-4906 (2014)

145. Lan, J.L., Liu, Y.C., Zhan, B., Lin, Y.H., Zhang, B., Yuan, X., Zhang, W., Xu, W., Nan, C.W.: Enhanced thermoelectric properties of $\mathrm{Pb}$-doped BiCuSeO ceramics. Adv. Mater. 25(36), 50865090 (2013)

146. Li, J., Sui, J., Pei, Y., Barreteau, C., Berardan, D., Dragoe, N., Cai, W., He, J., Zhao, L.-D.: A high thermoelectric figure of merit $\mathrm{ZT} \% 3 \mathrm{e} 1$ in Ba heavily doped $\mathrm{BiCuSeO}$ oxyselenides. Energy Environ. Sci. 5(9), 8543-8547 (2012)

147. Ohtaki, M.: Oxide thermoelectric materials for heat-to-electricity direct energy conversion. Novel Carbon Resour. Sci. Newsl. 3, $1-6$ (2010)

148. Hanbo, L., Ganhong, Z., Zhenxiang, D., Zhenheng, Y., Haiqiu, W., Yongqing, M.: Thermoelectric properties of $\mathrm{Sr}_{0.9} \mathrm{La}_{0.1} \mathrm{TiO}_{3}$ and $\mathrm{Sr}_{2.7} \mathrm{La}_{0.3} \mathrm{Ti}_{2} \mathrm{O}_{7}$ with $15 \% \mathrm{Ag}$ addition. J. Rare Earths 32(4), 314-319 (2014)

Publisher's Note Springer Nature remains neutral with regard to jurisdictional claims in published maps and institutional affiliations. 